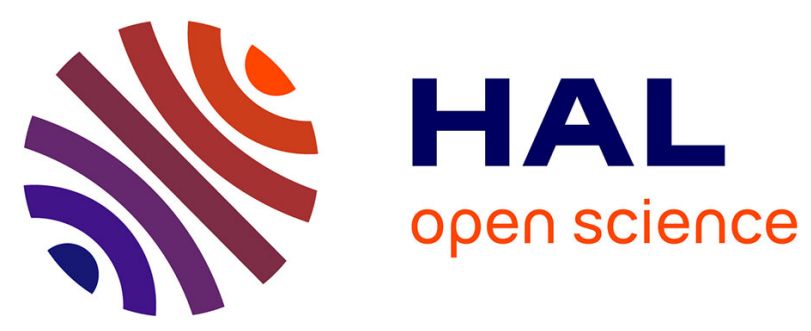

\title{
Deciphering the conditions of tochilinite and cronstedtite formation in CM chondrites from low temperature hydrothermal experiments
}

Lionel Vacher, Laurent Truche, François Faure, Laurent Tissandier, Régine Mosser-ruck, Yves Marrocchi

\section{To cite this version:}

Lionel Vacher, Laurent Truche, François Faure, Laurent Tissandier, Régine Mosser-ruck, et al.. Deciphering the conditions of tochilinite and cronstedtite formation in CM chondrites from low temperature hydrothermal experiments. Meteoritics and Planetary Science, 2019, 54 (8), pp.1870-1889. 10.1111/maps.13317 . hal-02357510

\section{HAL Id: hal-02357510 \\ https://hal.univ-lorraine.fr/hal-02357510}

Submitted on 10 Nov 2019

HAL is a multi-disciplinary open access archive for the deposit and dissemination of scientific research documents, whether they are published or not. The documents may come from teaching and research institutions in France or abroad, or from public or private research centers.
L'archive ouverte pluridisciplinaire HAL, est destinée au dépôt et à la diffusion de documents scientifiques de niveau recherche, publiés ou non, émanant des établissements d'enseignement et de recherche français ou étrangers, des laboratoires publics ou privés. 
Lionel G. Vacher ${ }^{\mathrm{a}^{*}}$, Laurent Truche ${ }^{\mathrm{b}}$, François Faure ${ }^{\mathrm{a}}$, Laurent Tissandier ${ }^{\mathrm{a}}$, Régine MosserRuck $^{\mathrm{c}}$ and Yves Marrocchi ${ }^{\mathrm{a}}$

${ }^{\text {a } C R P G, ~ C N R S, ~ U n i v e r s i t e ́ ~ d e ~ L o r r a i n e, ~ U M R ~ 7358, ~ V a n d o e u v r e-l e s-N a n c y, ~ F-54501, ~ F r a n c e ~}$ ${ }^{\mathrm{b}}$ ISTerre, UMR 5275 CNRS, Université Grenoble Alpes, 1381 rue de la Piscine, BP53 38041 Grenoble CEDEX 9, France

${ }^{\mathrm{c}}$ GeoRessources, UMR 7359 CNRS, Université de Lorraine, Campus Aiguillettes, 54506

Vandoeuvre-lès-Nancy, France

*Corresponding author: lvacher@crpg.cnrs-nancy.fr

Keywords: CM chondrites, hydrothermal experiments, cronstedtite, tochilinite 
17 Abstract-Tochilinite/cronstedtite intergrowths are commonly observed as alteration 18 products in $\mathrm{CM}$ chondrite matrices but the conditions under which they formed are still 19 largely under-constrained due to their scarcity in terrestrial environments. Here we report low 20 temperature $\left(80^{\circ} \mathrm{C}\right)$ anoxic hydrothermal experiments using starting assemblages similar to 21 the constituents of the matrices of the most pristine CM chondrite and S-rich and S-free 22 fluids. Cronstedtite crystals formed only in S-free experiments under circumneutral conditions 23 with the highest Fe/Si ratios. Fe-rich tochilinite with chemical and structural characteristics 24 similar to chondritic tochilinite was observed in S-bearing experiments. We observed a 25 positive correlation between the $\mathrm{Mg}$ content in the hydroxide layer of synthetic tochilinite and temperature, suggesting that the composition of tochilinite is a proxy for the alteration temperature in $\mathrm{CM}$ chondrites. Using this relation, we estimate the mean precipitation temperatures of tochilinite to be $120-160^{\circ} \mathrm{C}$ for $\mathrm{CM}$ chondrites. Given the different temperature ranges of tochilinite and cronstedtite in our experiments, we propose that Fe-rich tochilinite crystals resulted from the alteration of metal beads under S-bearing alkaline 31 conditions at $\mathrm{T}=120-160^{\circ} \mathrm{C}$ followed by cronstedtite crystals in formed by reaction of matrix amorphous silicates, metal beads, and water at low temperature $\left(50-120^{\circ} \mathrm{C}\right)$. 
C-type asteroids are the sources of undifferentiated carbonaceous meteorites and provide valuable information about the physicochemical conditions that prevailed in the solar protoplanetary disk. CM carbonaceous chondrites are fragments of these asteroids (Clark et al. 2010; Cloutis et al. 2011) and contain a significant amount of water (i.e., water/rock ratio = 0.4 upon accretion; Marrocchi et al. 2018), mainly as $\mathrm{OH}$ bound into phyllosilicates (Jarosewich 1990; Barber 1981). They are characterized by different degree of aqueous alteration, from moderately (CM2) to highly altered (CM1) (Zolensky et al. 1997; Rubin et al. 2007), and contain a variety of secondary phases produced through aqueous alteration processes, including carbonates, sulfides, oxides, and hydroxides (Bunch and Chang, 1980; Barber 1981; Tomeoka and Buseck, 1985; Zolensky et al. 1993; Brearley, 2006; Howard et al. 2009, 2011; Lee et al. 2014). The most characteristic secondary phases in CM chondrites are tochilinite-cronstedtite intergrowths (TCIs), occurring as complex assemblages dispersed throughout the chondrules, fine-grained rims and matrix (Fuchs et al. 1973; Tomeoka and Buseck 1985; Nakamura and Nakamuta 1996; Howard et al. 2015; Pignatelli et al. 2016, 2017). TCIs are ubiquitous in unheated CM chondrites and may be useful in deciphering the alteration conditions of CM parent bodies.

Since the first description of complex Fe-S-O alteration minerals in CM chondrites (i.e., as "poorly characterized phases"; Ramdohr 1963; Fuchs et al. 1973), numerous studies have sought to better understand the mineralogy and chemical properties of TCIs (Tomeoka and Buseck 1985; Mackinnon and Zolensky 1984; Zolensky and Mackinnon 1986; Nakamura and Nakamuta 1996; Palmer and Lauretta 2011; Pignatelli et al. 2016, 2017). Two types of TCIs have been defined based on morphology, mineralogy, and chemical composition (Nakamura and Nakamuta 1996): Type-I TCIs occur as rounded massive rims around Fe-Ni metal beads embedded in chondrules and comprise tochilinite with minor cronstedtite and goethite (Palmer and Lauretta 2011; Pignatelli et al. 2017), whereas Type-II TCIs occur as fibrous clusters in the matrix and comprise cronstedtite with minor tochilinite and magnetite (Pignatelli et al. 2017).

Tochilinite is a hydroxysulfide mineral with the general ideal formula of $2 \mathrm{Fe}_{1-x} \mathrm{~S}$. $n(\mathrm{Fe}, \mathrm{Mg}, \mathrm{Al}, \mathrm{Ca})(\mathrm{OH})_{2}$, where $0.08 \leq x \leq 0.28$ and $1.58 \leq n \leq 1.75$ (Zolensky and Mackinnon 1986; Gubaidulina et al. 2007). Its crystal structure is characterized by alternating brucite/amakinite-like $(\mathrm{Mg}, \mathrm{Fe})(\mathrm{OH})_{2}$ and mackinawite-like $(\mathrm{Fe}, \mathrm{Ni})_{1-x} \mathrm{~S}$ layers (Mackinnon and Zolensky 1984; Organova et al. 1988). Meteoritic tochilinite is believed to form during 
the first stage of aqueous alteration by dissolution of Fe-Ni metal or olivine/pyroxene by Sand Fe-rich fluids (Zolensky and Mackinnon 1986; Palmer and Lauretta 2011; Pignatelli et al. 2016). Thermodynamic simulations and hydrothermal experiments indicate that tochilinite precipitates under very reducing conditions $\left(\log f \mathrm{O}_{2} \approx-91\right.$ to -85$)$ in neutral-alkaline environments $(\mathrm{pH}=7.8-14)$, typically at $80-320^{\circ} \mathrm{C}$ (Kakos et al. 1994; Browning and Bourcier 1996; Kozerenko et al. 1996; Moroz et al. 1997; Gubaidulina et al. 2007; Peng et al. 2007; Peng and Jing 2014). Cronstedtite is a Fe-rich phyllosilicate (7 $\AA$ along its $c$-axis) with the general formula $\left(\mathrm{Fe}^{2+}{ }_{3-x} \mathrm{Fe}^{3+}{ }_{x}\right)\left(\mathrm{Si}_{2-x} \mathrm{Fe}^{3+}{ }_{x}\right) \mathrm{O}_{5}(\mathrm{OH})_{4}$, where $0 \leq x \leq 0.84$ (Hybler et al. 2000; Kogure et al. 2002; Pignatelli et al. 2013): $\mathrm{Fe}^{3+}$ is in tetrahedral coordination, and cronstedtite forms a solid solution with greenalite $\left[\left(\mathrm{Fe}^{2+} \mathrm{Fe}^{3+}\right)_{3} \mathrm{Si}_{2} \mathrm{O}_{5}(\mathrm{OH})_{4}\right]$ and chrysotile $\left[\mathrm{Mg}_{3} \mathrm{Si}_{2} \mathrm{O}_{5}(\mathrm{OH})_{4}\right]$ in CM chondrites (Velbel 2014). Some Type-II TCIs display euhedral crystal faces suggesting that such TCIs result from the pseudomorphism of olivine, pyroxene, and carbonates (Browning and Bourcier 1996; Lee et al. 2013; Pignatelli et al. 2016; Vacher et al. 2017). Laboratory experiments and thermodynamic calculations suggest that cronstedtite forms under less reducing conditions than tochilinite (i.e., $\log f \mathrm{O}_{2} \approx-75$ to -55 ) in neutral conditions $(\mathrm{pH}=7-8)$ from $\mathrm{Si}$ - and Fe-rich fluids at $50-120^{\circ} \mathrm{C}$ (Lantenois et al. 2005; Lanson et al. 2012; Pignatelli et al. 2013, 2014; Zolotov 2014).

The occurrence of tochilinite and cronstedtite as intergrowths suggests that (i) these minerals may precipitated under similar physicochemical conditions at some point (Pignatelli et al. 2016, 2017) and/ or (ii) one could have replaced the other during the CM parent body evolution. Their stability fields remain poorly constrained, and few laboratory experiments have investigated the formation of tochilinite and cronstedtite from starting products similar to those encountered in CM chondrites (Peng et al. 2007; Peng and Jing 2014). To fill this gap, we performed short-term (up to two months) anoxic hydrothermal experiments at $80^{\circ} \mathrm{C}$ by reacting synthetic glass powder of a composition similar to the primitive chondrite matrix, metal iron, and olivine with S-rich and S-free fluids. Specific attention was paid to the mineralogical and chemical characterization of the reaction products and the implications for the alteration conditions of CM chondrites. 


\section{"Synthetic GEMS-like" glass preparation}

100

Pristine CM chondrite matrix is mainly composed of amorphous silicate grains a few hundred nanometers in size that share many similarities with GEMS grains (glass with embedded metal and sulfides) observed in chondritic interplanetary dust particles (IDPs) (Bradley 1994; Keller and Messenger 2011; Leroux et al. 2015). We thus used an analogous starting material for our hydrothermal experiments. Synthetic glass (hereafter "synthetic GEMS-like glass") containing 51.82 wt.\% $\mathrm{SiO}_{2}, 25.80$ wt.\% $\mathrm{MgO}, 14.63$ wt.\% $\mathrm{Fe}_{2} \mathrm{O}_{3}, 5.59$ wt/\% $\mathrm{Al}_{2} \mathrm{O}_{3}$, and 1.88 wt.\% $\mathrm{CaO}$ (bulk analysis from SARM, Nancy, France), similar to natural GEMS grains (Leroux et al. 2015), was prepared from oxide carbonate powders $\left(\mathrm{SiO}_{2}\right.$, $\mathrm{MgCO}_{3}, \mathrm{Fe}_{2} \mathrm{O}_{3}, \mathrm{Al}_{2} \mathrm{O}_{3}$, and $\mathrm{CaCO}_{3}$ ) at CRPG (Nancy, France). The powder mixture was melted in platinum crucibles at $1550^{\circ} \mathrm{C}$ for $30 \mathrm{~min}$ and quenched in cold water. This quenched glass was crushed to a fine powder (particles of a few microns to a few hundred microns) in an agate mortar and pestle.

GEMS grains in IDPs contain rounded Fe-Ni metal grains believed to have formed in the hot inner regions of the solar protoplanetary disc by heating of amorphous silicate grains in a reduced environment at moderate temperatures ( $<730{ }^{\circ} \mathrm{C}$, Davoisne et al. 2006). We therefore reduced our glass using the sealed evacuated silica glass method (Skynner and Luce 1971): the synthetic glass powder was loaded into graphite crucibles placed in sealed evacuated silica glass tubes $\left(2 \times 10^{-2} \mathrm{mbar}\right)$ and heated at $1000^{\circ} \mathrm{C}$ for three days (Fig. 1a). After this reduction stage, a small amount of small beads of metallic iron (i.e., <1 vol.\%), with sizes of a few

\section{Hydrothermal experiments}

Hydrothermal experiments were performed by placing sample mixtures in Teflon® bowls within Parr ${ }^{\circledR}$ non-stirred pressure vessels. To remove oxygen trapped in the porosity of the Teflon ${ }^{\circledR}$ bowls, the bowls were pre-treated with a hydrazine solution $\left(20 \mathrm{ppm} \mathrm{N}_{2} \mathrm{H}_{2}\right)$ at 200 ${ }^{\circ} \mathrm{C}$ for one day. Oxygen gas was removed from the vessels according to the reaction (Dargent et al. 2015):

$$
\mathrm{O}_{2}(\mathrm{~g})+\mathrm{N}_{2} \mathrm{H}_{2}(\mathrm{aq})=2 \mathrm{H}_{2} \mathrm{O}(\mathrm{aq})+\mathrm{N}_{2}(\mathrm{~g})
$$


The reactors were then cleaned in a glove box under inert argon atmosphere $\left(<1 \mathrm{ppm} \mathrm{O}_{2}\right)$ using $1 \mathrm{M} \mathrm{HCl}$ and rinsed several times with MilliQ water. The solid starting products (i.e., 1 g comprising (i) synthetic GEMS-like glass, (ii) San-Carlos olivine $\left[\mathrm{Mg}_{1.8} \mathrm{Fe}_{0.19} \mathrm{Ni}_{0.01} \mathrm{SiO}_{4}\right]$ grains typically in the size range $20-50 \mu \mathrm{m}$, and (iii) spherical iron metal blobs $<10 \mu \mathrm{m}$ in diameter from Sigma Aldrich) were mixed in various proportions (see Table 1 and Fig. 2a) under inert Ar atmosphere in the glove box. The sample mixtures were then loaded together with $10 \mathrm{~mL}$ of a synthetic saline solution $\left(2.1 \mathrm{mM} \mathrm{NaCl}, 0.4 \mathrm{mM} \mathrm{MgCl}_{2}\right.$ and $\mathrm{CaCl}_{2}, \mathrm{pH}=6.5$ at $25^{\circ} \mathrm{C}$, Table 1) into the Teflon ${ }^{\circledR}$ Parr $®$ bombs (Fig. 2b).

Previous laboratory experiments demonstrated that tochilinite and cronstedtite preferentially precipitate under alkaline S-rich (the best tochilinite specimens at $\mathrm{pH} \approx 11$; Kozerenko et al. 2001) and neutral S-free environments $(\mathrm{pH} \approx 7$; Pignatelli et al. 2013), respectively. Hence, we separated our experiments into two sets: the first with an alkaline environment created by adding $10 \mathrm{mM} \mathrm{Na}_{2} \mathrm{~S}$ to the initial saline solution $\left(\mathrm{pH}=11.5\right.$ at $25^{\circ} \mathrm{C}$ ) and the second with a circumneutral environment employing only the initial salty solution $\left(\mathrm{pH}=6.5\right.$ at $25^{\circ} \mathrm{C}$, Table 1, Fig. 2b). The water/rock ratio was set to 10 (by weight) and the vessels were heated at $80^{\circ} \mathrm{C}$ and at saturated vapor pressure in a furnace for 30 or 60 days. The two sets of experiments are summarized in Table $\mathbf{1}$ and in Figure 2.

At the end of the experiments, the vessels were removed from the furnace and quenched in cold water. The vessels were opened and the solid products were dried in a glove box under argon atmosphere at room temperature.

\section{Solution analysis}

The run solutions were immediately extracted from the vessels after quenching, filtered at $0.02 \mu \mathrm{m}$, and separated into two distinct aliquots for (i) $\mathrm{pH}$ measurement at room temperature, and (ii) inductively coupled plasma optical emission spectrometry (ICP-OES) analyses. ICPOES analyses were performed after dilution in $\mathrm{HNO}_{3}(2$ vol.\%) to determine the concentration of dissolved $\mathrm{Al}, \mathrm{Ca}, \mathrm{Fe}, \mathrm{K}, \mathrm{Mg}, \mathrm{Na}$, and $\mathrm{Si}$ (detection limit $<50 \mu \mathrm{g} / \mathrm{L}$ ). Because dissolved $\mathrm{Al}, \mathrm{Fe}$, and $\mathrm{Mg}$ were below the detection limit in run solutions G-2, GO-2, and GOI-2, additional aliquots (without dilution) were collected and measured by inductively coupled plasma mass spectrometry (ICP-MS) at SARM (Nancy, France) with a detection limit $<1 \mu \mathrm{g} / \mathrm{L}$. 
Back-scattered electron (BSE) images of the solid products were obtained at GeoRessources (Nancy, France) using a JEOL J7600F Field Emission Scanning Electron Microscope (FE-SEM) equipped with an Oxford EDS (Energy Dispersive X-ray spectrometer). SEM observations were performed with an accelerating voltage of $15 \mathrm{kV}$. EDS analyses were made with an accelerating voltage of $15 \mathrm{kV}$ and a beam current of $100 \mathrm{nA}$. Chemical analyses were calibrated using the following natural minerals: albite for $\mathrm{Al}$, hematite for $\mathrm{Fe}$ and $\mathrm{O}$, olivine for $\mathrm{Mg}$, orthoclase for $\mathrm{Si}$, wollastonite for $\mathrm{Ca}$ and $\mathrm{FeS}_{2}$ for $\mathrm{S}$.

Solid products were prepared for transmission electron microscopy (TEM) and scanning transmission electron microscopy (STEM) by crushing them in an agate mortar, dispersing them in an ethanol solution under ultrasonic treatment, and evaporating the solution on a holey carbon film placed on a 200 mesh copper grid. TEM imaging, EDX analyses and selected area electron diffraction (SAED) were performed at IJL (Nancy, France) using a JEM-ARM 200F cold-field emission gun TEM/STEM operating at $200 \mathrm{kV}$ and equipped with a spherical aberration $(\mathrm{Cs})$ probe corrector $(0.19$ and $0.078 \mathrm{~nm}$ point resolution in TEM and STEM mode, respectively). Qualitative measurement of elements was obtained using the Cliff-Lorimer ratio method. Electron-transparent cross-sections of samples from GS-2 and GOS-2 were prepared by using a FEI Versa 3D DualBeam field emission (FIB/SEM) at the F.M.E company (Nancy, France).

The hydrated/porous nature and the small sizes (less than $1 \mu \mathrm{m}$ ) of the secondary mineral phases synthesised during our hydrothermal experiments make the SEM-EDS analyses difficult. However, we excluded all the analyses with a total lower than $65 \mathrm{wt} \%$ (lowest total measured in the Fe, Si-rich layer in the S-bearing experiments) and higher than $102 \mathrm{wt} . \%$. In addition, all the representative chemical compositions reported in the Tables S1 and S3 were normalized to $100 \%$.

X-ray diffraction (XRD) data were collected at room temperature with a PANalytical X'pert PRO diffractometer (goniometer $\theta-2 \theta$ ), using a $\mathrm{Cu}$ tube, a $\mathrm{Ge}$ (111) incident-beam monochromater $\left(\lambda=1.5406 \AA\right.$ ) and a X'Celerator detector (scanning line detector 1D, $2.122^{\circ}$ active length) at CRM laboratory (University of Lorraine, France). X-ray patterns were collected on bulk-rock samples, with $2.122^{\circ}$ active length, using a scan step of $0.0167^{\circ}(2 \theta)$ and a time of measurement for each sample of $90 \mathrm{~min}, 2 \theta_{\min }=5^{\circ}$ to $2 \theta_{\max }=70^{\circ}$. 
$19735 \mathrm{kV}$ accelerating voltage and $45 \mathrm{~mA}$ current (CRM laboratory, University of Lorraine,

198 France). X-ray patterns were collected on bulk-rock samples, using a scan step of $0.007^{\circ}(2 \theta)$

199 and a time of measurement for each sample of $90 \mathrm{~min}, 2 \theta_{\min }=5^{\circ}$ to $2 \theta_{\max }=70^{\circ}$. 


\section{Circumneutral S-free experiments}

\section{Solid phase characterization}

Alteration of primary phases

SEM observations of olivine and synthetic GEMS-like grains do not reveal obvious signs of dissolution on grain surfaces or along grain boundaries (e.g., disk-shaped grains or the formation of a gel layer) at micrometer scale (Fig. S1). However, this lack of evidence does not exclude minor signs of dissolution at nanometer scale, but further FIB-TEM investigations are required. In contrast, corrosion textures characterized by thin layers of newly formed material are present at the edges of iron metal grains (Fig. 3b).

\section{Secondary mineral paragenesis}

SEM-TEM observations of the S-free run products reveal the presence of two new mineral phases synthesized during the hydrothermal experiments. The first is present in the run products of all three $\mathrm{S}$-free experiments and is composed of a fibrous $\mathrm{Fe}-\mathrm{Si}$-rich mineral occurring in layers $<1 \mu \mathrm{m}$ thick around native iron metal (Fig. 3b). This phase has a composition close to berthierine or greenalite $(\mathrm{n}=2$, Fig. 3c, Table S1).

The second new phase is an iron oxide that occurs only in experiment GOI as grains of a few tens of microns (Fig. 3a). This phase is easily identifiable at contacts with iron metal grains. SEM-EDS analyses indicate that this iron oxide has a composition close to goethite: $65.4 \pm 2$ wt.\% Fe, $31.1 \pm 1.5$ wt.\% O, $3.2 \pm 0.5$ wt.\% Si, $0.1 \pm 0.3$ wt.\% $\mathrm{Mg}$, and $0.03 \pm 0.1$ wt. $\% \mathrm{Ca}(\mathrm{n}=11,1 \sigma$ errors; Fig. 3c, Table S1).

\section{Cronstedtite precipitation}

Detailed TEM investigation of experiment GOI reveals rare triangular crystals of cronstedtite $<1 \mu \mathrm{m}$ in size that were not detected by X-ray diffraction (XRD) (Fig. 4a, b).

228 Cronstedtite was not detected in the products of experiments $G$ and GO. TEM-EDS measurements show that these crystals contain of $52.8 \pm 1.9$ wt.\% Fe, $36.9 \pm 1.7$ wt.\% O, 8.3

$230 \pm 0.4$ wt.\% Si, $1.4 \pm 0.2$ wt. $\%$ Al, $0.4 \pm 0.1$ wt. $\% \mathrm{Mg}$, and $0.2 \pm 0.1$ wt.\% $\mathrm{Ca}(\mathrm{n}=6,1 \sigma$ errors; Fig. 4a, Table S1). To calculate the average structural formula of cronstedtite, the 
233 Pignatelli et al. (2013). Hence, based on a total of 7 oxygen atoms, we obtained the mean 234 empirical formula of cronstedtite to be $\left(\mathrm{Fe}^{2+}{ }_{2} \mathrm{Fe}^{3+}{ }_{0.9} \mathrm{Mg}_{0.1}\right)\left(\mathrm{Si}_{1.1} \mathrm{Al}_{0.2} \mathrm{Fe}^{3+}{ }_{0.7}\right) \mathrm{O}_{5}(\mathrm{OH})_{4}$. The 235 SAED pattern along the [001] zone axis of cronstedtite (Fig. $4 d$ ) reveals: (i) strong $\mathrm{h}-\mathrm{k}=3 \mathrm{n}$ 236 diffractions (e.g., 110, 300, in hexagonal indexing) and weak $\mathrm{h}-\mathrm{k} \neq 3 \mathrm{n}$ diffractions (e.g., 237 100, 010, 200), and (ii) a hexagonal cell with parameters $\mathrm{a}=\mathrm{b}=0.54 \mathrm{~nm}$ (Fig. 4c, d). The 238 SAED pattern along the [010] zone axis indicates the cell parameter $\mathrm{c}=0.71 \mathrm{~nm}(\mathbf{F i g}$. 4e, f), 239 consistent with typical terrestrial (Hybler et al. 2000) and meteoritic cronstedtite (i.e., 240 polytype 1T; Pignatelli et al. 2018).

\section{Solution chemistry}

The evolution of $\mathrm{Si}, \mathrm{Ca}, \mathrm{Mg}$, and $\mathrm{Fe}$ concentrations in the neutral $\mathrm{S}$-free experiments are presented in Fig. 5a-c and Table S2. After two months, Si concentrations reached a steady state (within errors) at 0.8 and $0.4 \mathrm{mM}$ in experiments $\mathrm{G}$ and GOI, respectively (Fig. 5a, c). In experiment GO, the Si concentration increased to $1.2 \mathrm{mM}$ after one month, then decreased to $0.6 \mathrm{mM}$ after two months (Fig. 5b). Calcium concentrations remained rather constant at $\sim 0.3$ $\mathrm{mM}$ in experiments $\mathrm{G}$ and $\mathrm{GO}$ and at $\sim 0.25 \mathrm{mM}$ in experiment GOI (Fig. 5a-c). Magnesium concentrations decreased from 0.4 to $\sim 0.05 \mathrm{mM}$ over two months in all S-free experiments (Fig. 5a-c). Iron and $\mathrm{Al}$ concentrations remained very low, $\sim 10^{-4}$ to $10^{-3} \mathrm{mM}$, after two months in all the experiments (Fig. 5a-c, Table S2). The elevated Fe concentrations (from 23 to $78 \mathrm{mM}$ ) after one month are surprising and may reflect a strong solution disequilibrium with respect to Fe-bearing minerals (e.g. magnetite, greenalite and cronstedtite) expected to be stable under our experimental. Indeed, thermodynamic simulations performed with PhreeqC software together with the llnl database indicate that dissolved iron concentration should remain within the $10^{-4}$ to $10^{-6} \mathrm{mM}$ range under our experimental conditions (i.e., $\mathrm{T}=80^{\circ} \mathrm{C}, \mathrm{pH}=6-8$ and $\log f \mathrm{O}_{2}=-60$ ) if the fluid is in equilibrium with magnetite, greenalite or cronstedtite. Thus, the elevated Fe concentrations observed in our run solutions either result from (i) a precipitation delay of $\mathrm{Fe}$-bearing minerals (causing an oversaturation of $\mathrm{Fe}$ ) or (ii) a contamination/filtration issue. In the absence of a continuous monitoring of solution composition over time, it is difficult to provide a robust explanation for this observation.

The $\mathrm{pH}$ of the solutions increased progressively up to $\mathrm{pH}=8$ in experiments GO and GOI, 


\section{Solid Phase characterization}

Alteration of primary phases

SEM observations of the primary phases after reaction do not reveal obvious signs of dissolution on olivine and synthetic GEMS-like grains at the micrometer scale (Fig. S1). In contrast, a thin $(1-2 \mu \mathrm{m})$ iron oxide layer penetrates the surfaces of iron metal grains.

\section{Secondary mineral paragenesis}

SEM observations of products of the S-bearing experiments show newly formed synthetic assemblages 2-3 $\mu \mathrm{m}$ thick around iron metal beads (not detected by XRD analysis) (Fig. 6a, b). This mineral assemblage can be separated into three different layers according to the textures observed: (i) a compact layer penetrates the metal grains and exhibits irregular contacts with the iron metal, (ii) a secondary rim with an acicular/fibrous texture surrounds the compact layer, and (iii) a fibrous layer surrounds the acicular layer (Fig. 6a, b).

The TEM chemical profile of the alteration rims in the GS-2 FIB-produced cross section (Fig. 7a, e) shows chemical zoning of $\mathrm{Fe}, \mathrm{O}, \mathrm{S}$, and $\mathrm{Si}$ within the different layers (Fig. 7b-e). The inner compact zone $\left(\mathrm{Z}_{1}\right)$ is Fe- and O-rich (Fig. 7c) and is characterized by homogeneous $\mathrm{Fe}, \mathrm{O}, \mathrm{Si}$, and $\mathrm{S}$ concentrations averaging 61.6, 29.8, 4.8, and $3.7 \mathrm{wt} \%$, respectively $(\mathrm{n}=3$, Fig. 5c). The acicular/fibrous layer $\left(Z_{2}\right)$ is Fe- and S-rich is compositionally zoned: Fe and $S$ concentrations are highest in the center of the layer (67.5 and $23.2 \mathrm{wt} \%$, respectively) and decrease towards the surrounding layers (down to $\sim 62$ and $9.5 \mathrm{wt} . \%$, respectively), whereas O and Si concentrations are lowest in the center of the layer (8.4 and $0.9 \mathrm{wt} . \%$, respectively) and increase towards the surrounding layers (reaching 24.5 and 4 wt.\%, respectively) (n $=5$, Fig. 7e). The outer zone $\left(\mathrm{Z}_{3}\right)$ is also Fe- and O-rich, but contains higher $\mathrm{O}$ and $\mathrm{Si}$ concentrations (39.4 and 10.6 wt.\%, respectively) and lower Fe and S concentrations (49.3 and 0.7 wt.\%, respectively) than layers $Z_{1}$ and $Z_{2}$ (Fig. 7e). A layer similar to $Z_{3}$ occurs between layers $Z_{1}$

\section{Tochilinite precipitation} and $\mathrm{Z}_{2}$ with variable thickness (Fig. 7a-d).

TEM imaging of the acicular Fe-S-rich layer $\left(Z_{2}\right)$ indicate that this assemblage comprises many needle-shaped crystals several hundreds of nanometers in size (Fig. 8a, b). Highresolution TEM (HRTEM) images suggest that these crystals grew perpendicular to the 
surface of the iron metal grain (Fig. 8b-c). However, the corresponding SAED pattern

300 (collected from a small area of the needle-shaped crystals) indicates that this assemblage is poorly crystalline and shows several strong and weak broad rings at $d$-spacings of $0.54,0.27$, 0.25 and $0.18 \mathrm{~nm}$, compatible with tochilinite reflections (Fig. 8d; Organova et al. 1973; 303 Pekov et al. 2013). Furthermore, HRTEM images indicate lattice fringes of $0.54 \mathrm{~nm}$ and SAED patterns show strong (002) diffraction spots along the $\mathrm{c}^{*}$ axis consistent with tochilinite (Fig. 8e, f) (Mackinnon and Zolensky 1984; Organova et al. 1988; Kakos et al. 1994). EDX analyses of isolated acicular crystals show that they contain variable concentrations of $\mathrm{Fe}$ and $\mathrm{O}$, with the average composition $57.9 \pm 9.4$ wt.\% $\mathrm{Fe}, 18.4 \pm 5.7$ wt.\% O, $17.9 \pm 1.5$ wt.\% S, $3.9 \pm 2$ wt.\% Si, $0.7 \pm 0.8$ wt.\% Ca, and $0.6 \pm 0.8$ wt. $\% \mathrm{Mg}(\mathrm{n}=$ 6, $1 \sigma$ errors; Fig. 6c, Table S3). These analyses demonstrate that the acicular crystals forming the intermediate rims around iron grains are tochilinite with a mean empirical formula equivalent to $2\left(\mathrm{Fe}_{0.88} \mathrm{~S}\right) \cdot 2.1\left(\mathrm{Fe}_{0.96} \mathrm{Mg}_{0.04}\right)(\mathrm{OH})_{2}$ when normalized to $2 \mathrm{~S}$ atoms.

\section{Solution chemistry}

314 Si and Ca concentrations of the experimental solutions are plotted as a function of elapsed 315 time in Fig. 9a-c and Table S2. Si concentrations in the solution increased over two months 316 to reach a steady state (within error) at 1.7 and $1.9 \mathrm{mM}$ in experiments $\mathrm{GS}$ and GOS, respectively (Fig. 9a, b). In experiment GOIS, the Si concentration increased to $1.1 \mathrm{mM}$ after 318 one month, then decreased to $0.3 \mathrm{mM}$ after two months (Fig. 9c). Ca concentrations decreased 319 from $0.4 \mathrm{mM}$ to $0.01-0.02 \mathrm{mM}$ after two months in all the S-bearing experiments (Fig. 9a-c). $320 \mathrm{Fe}, \mathrm{Mg}$, and $\mathrm{Al}$ concentrations are very low, with most measurements below the ICP-OES 321 detection limit (i.e., $<50 \mu \mathrm{g} / \mathrm{L}$, Table S2).

The $\mathrm{pH}$ of the S-rich alkaline solutions decreased from 11.5 to 7.7 and 8.8 over two months in experiments GS and GOS, respectively (Fig. 9d). In experiment GOIS, the pH decreased to 6.4 after one month, then increased to 9.7 after another month (Fig. 9d). 
These low temperature hydrothermal experiments aimed to investigate the formation of meteoritic tochilinite and cronstedtite from starting products similar to the constituents of the matrices of the most pristine $\mathrm{CM}$ chondrite. We first explore the conditions of formation of tochilinite and cronstedtite by comparing our results to previous works on TCIs in CM chondrites and from laboratory experiments. We then estimate the temperatures of formation of $\mathrm{CM}$ tochilinite based on their $\mathrm{Mg}$ concentration and discuss the implications of these temperatures on understanding the thermal evolution of the CM parent body. We finally conclude the discussion by considering the possibility that tochilinite and cronstedtite may coprecipitate under similar physicochemical conditions for at least a short time.

\section{Conditions of cronstedtite formation}

Cronstedtite crystals formed only in the experiment with the highest Fe content (with GEMS-like grains, forsterite, and $\mathrm{Fe}^{0}$ in equal proportions by mass; $\mathrm{Fe}_{\mathrm{tot}} / \mathrm{Si}=2.7$ ). This result is in good agreement with the preferential formation of 1:1 (TO) iron phyllosilicates (i.e., cronstedtite/greenalite) reported for experiments with $\mathrm{Fe} / \mathrm{Si}$ ratios of 2.25 , whereas experiments with lower Fe/Si (i.e., 0.75) produced 2:1 (TOT) iron phyllosilicates (Mizutani et al. 1991). It thus appears that the $\mathrm{Fe} / \mathrm{Si}$ ratio could be a key parameter controlling the formation of cronstedtite, with the presence of $\mathrm{Fe}^{0}$ imposing reducing condition $\left(\mathrm{H}_{2}\right.$ is a byproduct of $\mathrm{Fe}^{\circ}$ oxidation under anoxic conditions) and providing $\mathrm{Fe}^{2+}$ for cronstedtite precipitation. In addition, experiments and thermodynamic modeling have shown that cronstedtite crystals form under specific conditions: $\mathrm{pH}=7-8, \log f \mathrm{O}_{2} \approx-65$ to -60 (estimated from the measured $\mathrm{Si}$ concentrations in solutions from experiment GOI and the calculated stability field of cronstedtite at $80^{\circ} \mathrm{C}$ from Pignatelli et al. 2014, Fig. 10), and below $100^{\circ} \mathrm{C}$ because the stability field of cronstedtite decreases with increasing temperature (Fig. 10; Rivard 2001; Schulte and Shock 2004; McAlister and Kettler 2008; Zolotov 2014; Pignatelli et al. 2013, 2014).

Our results indicate that the cronstedtite formed by reaction between synthetic GEMSlike glass, metallic iron, and water. Similarly, in the least altered CM chondrite Paris (Hewins et al. 2014, Marrocchi et al., 2014), (i) the occurrence of platy cronstedtite in association with amorphous silicates and serpentines and (ii) the progressive iron enrichment of the matrix 
resulting from the dissolution of Fe-Ni metal beads (Leroux et al. 2015) suggest that cronstedtite formed from fluid reaction with matrix amorphous silicates, Fe-Ni metal beads, and water (melted accreted ices) in CM chondrites.

In $\mathrm{CM}$ chondrites, cronstedtite-like crystals probably correspond to a ternary solid solution and/or mixture between greenalite $\left(\left(\mathrm{Fe}^{2+} \mathrm{Fe}^{3+} \mathrm{Mg} \square\right)_{3}(\mathrm{SiAl})_{2} \mathrm{O}_{5}(\mathrm{OH})_{4}\right.$; Guggenheim et al. 1982), chrysotile $\left(\mathrm{Mg}_{3} \mathrm{Si}_{2} \mathrm{O}_{5}(\mathrm{OH})_{4}\right)$ and cronstedtite end members (Velbel 2014, Pignatelli et al. 2015). However, pure cronstedtite (i.e., cronstedtite with crystallo-chemical characteristics similar to those reported for terrestrial one) has recently been identified and characterized in CM Paris (Pignatelli et al. 2017, 2018). The chemical composition of our synthetic cronstedtite is in good agreement with both terrestrial and pure cronstedtite in CM Paris (Hybler et al. 2000; Pignatelli et al. 2018) (see Fig. 3c). Thus, cronstedtite in CM Paris probably formed under similar conditions to those investigated herein: i.e., high $\mathrm{Fe} / \mathrm{Si}$ ratio (resulting from the progressive incorporation of $\mathrm{Fe}$ into the matrix by dissolution of iron metal/kamacite and Fe-sulfide grains and precipitation of Fe-rich phyllosilicate, Leroux et al. $2015), \sim 80^{\circ} \mathrm{C}$, and in a circumneutral environment $(\mathrm{pH}=7-8)$.

\section{Experimental and natural conditions of tochilinite formation}

\section{Condition of tochilinite formation}

Few studies have succeeded in synthesizing ( $\mathrm{Fe}, \mathrm{Mg}$ )-tochilinite with $\mathrm{Fe}$ and $\mathrm{Mg}$ concentrations similar to those in meteoritic tochilinite (see overview in Tables $\mathbf{2}$ and $\mathbf{S 4}$; Kozerenko et al. 1996, 2001; Chistyakova et al. 2006). In CM chondrites, tochilinite is Ferich (40-58 wt.\% Fe) and the $\mathrm{Mg}$ content of its brucite/amakinite-like layer is low (1-5 wt.\% Mg, Table S4; Palmer and Lauretta 2011; Pignatelli et al. 2017). Kozerenko et al. (1996) produced Fe-rich tochilinite in low temperature $\left(80^{\circ} \mathrm{C}\right)$ hydrothermal experiments by depletion of $\mathrm{Mg}$ in solution. Chistyakova et al. (2006) and Gubaidulina et al. (2007) synthesized Fe-rich tochilinite crystals in multiple series of experiments at $160-180^{\circ} \mathrm{C}$ with various $\mathrm{Mg}$ contents in the initial mixture (0.67-4.17 mmol; Gubaidulina et al. 2007), but yielded minor $\mathrm{Mg}$ contents in the brucite layer $(\mathrm{nMg}=0.02-0.36$, where $\mathrm{nMg}$ is $\mathrm{Mg}$ content in the brucite layer normalized to $1 \mathrm{~S}$ ). However, in these laboratory studies, iron was directly supplied in solution as dissolved $\mathrm{Fe}^{2+}\left(\mathrm{FeCl}_{2}\right.$ solution) and not by dissolution of $\mathrm{Fe}-\mathrm{Ni}$ metal beads as is the case in primitive chondritic material. Furthermore, these studies do not provide the source of Mg in their starting products (Kozorenko et al. 2001; Chistyakova et al. 2006; 
Gubaidulina et al. 2007).

We produced tochilinite from the alteration of synthetic glass and metallic iron, valuable analogues of the amorphous silicates and $\mathrm{Fe}-\mathrm{Ni}$ metal beads found in $\mathrm{CM}$ chondrite matrices (Leroux et al. 2015). Dissolution of our synthetic glass is confirmed by the presence of dissolved $\mathrm{Si}$ in all run solutions, especially experiments using only GEMS-like glass as the starting material (Table S2), and the presence of Al in all S-free run solutions. We also noted that $\mathrm{Si}$ concentrations are higher in S-bearing than S-free experiments, whereas the opposite is observed for Mg (see Table S2). The difference in Si concentration is probably related to the different $\mathrm{pH}$ values of the initial solutions, as glass dissolution increases with increasing $\mathrm{pH}$ in neutral-alkaline conditions (Declercq et al. 2013; Vienna et al. 2018), whereas the dissolved $\mathrm{Mg}$ concentration is controlled by the precipitation of secondary $\mathrm{Mg}$-bearing minerals such as brucite (not detected) and/or tochilinite in S-bearing alkaline environments (Zolotov 2014).

Tochilinite synthesized in this study displays chemical and textural similarities to meteoritic tochilinite, such as (i) low $\mathrm{Mg}$ content (0-1.9 wt.\% or $0.5 \pm 0.7 \mathrm{wt} . \% \mathrm{Mg}, 1 \sigma, \mathrm{n}=$ 6, Table S4), (ii) acicular morphology (Fig. 8b, Lee and Ellen 2008; Haack et al. 2012), and (iii) preferential occurrence around iron metal grains (Figs. 6a, b and 7a; Palmer and Lauretta 2011). To our knowledge, this is the first time that tochilinite has been synthesized with characteristics so close to those of meteoritic tochilinite and from experimental conditions analogous to those of CM chondrite alteration. Peng and Jing (2014) also precipitated tochilinite from synthetic (Fe-, $\mathrm{Mg}-, \mathrm{Si}-, \mathrm{Al}-$, and Ni-rich) metal particles under high $\mathrm{pH}$ and $\mathrm{S}$ concentrations $\left(\mathrm{pH}=13-14,\left[\mathrm{~S}^{2-}\right]=10^{-2}\right.$ to $\left.10^{-1} \mathrm{~mol} / \mathrm{L}\right)$ at $110-160^{\circ} \mathrm{C}$, but their synthetic mineral contained more $\mathrm{Mg}(\mathrm{nMg}=0.46,1 \sigma=0.1, \mathrm{n}=4)$ than $\mathrm{CM}$ tochilinite.

In CM chondrites, most tochilinite in Type-I TCIs formed during the earliest stages of alteration from dissolution of kamacite by a S-rich fluid under alkaline conditions and temperatures up to $130^{\circ} \mathrm{C}$ (Mackinnon and Zolensky 1984; Kozerenko et al. 2001; Palmer and Lauretta 2011; Pignatelli et al. 2016, 2017). In our S-bearing experiments, Fe-rich tochilinite systematically surrounds iron metal grains, regardless of the starting materials and the proportion of metallic iron (Fig. 6a, b). Based on our SEM and TEM observations, we propose that the formation of tochilinite is induced by dissolution-precipitation reactions occurring at the metallic iron (or kamacite)-tochilinite interface as:

$$
3.8 \mathrm{Fe}(\mathrm{s})+0.08 \mathrm{Mg}^{2+}+2 \mathrm{HS}^{-}+1.84 \mathrm{H}^{+}+4.2 \mathrm{H}_{2} \mathrm{O}=2\left(\mathrm{Fe}_{0.88} \mathrm{~S}\right) \cdot 2.1\left(\mathrm{Fe}_{0.96} \mathrm{Mg}_{0.04}\right)(\mathrm{OH})_{2}(\mathrm{~s})
$$

[Tochilinite] $+3.98 \mathrm{H}_{2}(\mathrm{~g}) . \quad\left(\mathrm{HS}^{-}\right.$is the dominant sulfur species at $\left.\mathrm{pH}=8-11\right)$ (2) Due to the low solubility of secondary iron-bearing minerals, particularly tochilinite, the reaction is Fe-conservative under our experimental conditions, as evidenced by the constant 
426 and very low iron content of the reacting fluids. We also propose that the coupling between

427 iron dissolution and tochilinite precipitation is due to the interplay between substrate428 mediated nucleation and solution chemistry at the reaction front (Figs. 6 and 7). This is 429 texturally evident, as very small tochilinite crystallites grew inside the native-iron dissolution 430 pits and perpendicular to the reaction front. The proximity of the source and sink of iron 431 suggests that tochilinite nucleates easily and probably grows faster than the rate of iron 432 dissolution.

433 Tochilinite precipitation leads to a decrease in $\mathrm{S}$ concentration (i.e., consumption of all 434 the S initially in the fluid, Fig. 9d, Table S2). Once sulfide activity is no longer sufficient to 435 sustain tochilinite precipitation, Fe-Si-rich phyllosilicates are formed around tochilinite (e.g., 436 greenalite and/or cronstedtite). Similarly, the outer parts of Type-I TCI rims in CM Paris are 437 mainly composed of Fe-silicates similar to cronstedtite (Pignatelli et al. 2016), though in our 438 experiments, the Fe-Si-rich fibrous phase bordering tochilinite (Fig. 6a, b) is more similar to 439 greenalite than cronstedtite (Fig. 6c, Table S1). These textural and chemical arguments 440 provide clear evidence for the fluid-mediated precipitation of tochilinite. 


\section{Tochilinite: a proxy of the thermal history of CM chondrites?}

The synthetic tochilinite formed during our hydrothermal experiments was almost entirely made up of amakinite layers (i.e., $96 \% \mathrm{Fe}$ in the hydroxide layer), with minor $\mathrm{Mg}(4 \%)$. Other tochilinite syntheses at $80-130^{\circ} \mathrm{C}$ show comparable Fe contents, with all $\mathrm{Fe}$ in the hydroxide layer (Kozerenko et al. 1996, 2001), whereas those at a temperature of $>130^{\circ} \mathrm{C}$ have $30-70 \%$ Mg for $n=1.5-1.9$ in the tochilinite formula (Kakos et al. 1994; Kozerenko et al. 2001; Chistyakova et al. 2006; Gubaidulina et al. 2007; Peng and Jing 2014). It has been proposed that Fe-tochilinite is metastable, with a kinetically controlled formation that requires depletion of $\mathrm{Mg}^{2+}$ from solution and sufficiently high $\mathrm{Fe}^{2+}$ and $\mathrm{S}^{2-}$ activities at low temperature (Kozerenko et al. 2001; Peng et al. 2007; Pekov et al. 2013). Nevertheless, Kozerenko et al. (2001) demonstrated that the two main parameters controlling the stability field of tochilinite are sulfide concentration and temperature. At $\mathrm{S}^{2-}$ concentrations between $1 \times 10^{-3}$ and $5 \times 10^{-}$ ${ }^{5} \mathrm{~mol} / \mathrm{L}, \mathrm{Fe}$-tochilinite is stable up to $130^{\circ} \mathrm{C}$, and $(\mathrm{Mg}, \mathrm{Fe})$-tochilinite is the dominant phase at $130-320^{\circ} \mathrm{C}$ in the mackinawite-magnetite-pyrrhotite paragenesis (Kozerenko et al. 2001). Other experiments above $130^{\circ} \mathrm{C}$ produced tochilinite with variable $\mathrm{nMg}$ contents, ranging from 0.26 at $160-180^{\circ} \mathrm{C}$ to 0.66 at $200^{\circ} \mathrm{C}$, but none with only amakinite layers (Kakos et al. 1994; Kozerenko et al. 2001; Chistyakova et al. 2006; Peng and Jing 2014).

In $\mathrm{CM}$ chondrites, tochilinite has low concentrations of $\mathrm{Mg}$, ranging from 1.6 to $4.5 \mathrm{wt} \%$ (Palmer and Lauretta 2011; Pignatelli et al. 2017). This difference in composition is also correlated with degree of alteration of CM chondrites, which could reflect more availability of $\mathrm{Mg}$ in solution from the dissolution of forsterite/pyroxene precursors (Hanowski and Brearley 2001). Nevertheless, no strong relationships have been established experimentally between the Mg content in the starting products and that in tochilinite (Chistyakova et al. 2006). This discrepancy is evident in the meteoritic tochilinite of CM Paris, which displays only minor $\mathrm{Mg}$ in its structural formula ( $\mathrm{Mg}=1.6 \mathrm{wt} \%$, Table S4) although it is thought to have formed by the pseudomorphism of ferromagnesian silicate precursors (Pignatelli et al. 2016, 2017), so there should have been abundant $\mathrm{Mg}$ available.

Thus, temperature could be the most important control on the $\mathrm{Mg}$ content in the brucite/amakinite-like layer of tochilinite. Plotting the $\mathrm{nMg}$ content of the hydroxide layer of synthetic tochilinite as a function of synthesis temperature reveals a positive trend defined by $\mathrm{T}=175.9( \pm 44.6) \times \mathrm{nMg}+100.4( \pm 17.3)\left(\mathrm{r}^{2}=0.72, \mathrm{n}=8\right)($ Fig. 11, Table S4). Using this correlation, meteoritic tochilinite with $\mathrm{nMg}$ contents of $0.12-0.32$ (Table S4, Palmer and Lauretta 2011; Pignatelli et al. 2017) correspond to mean precipitation temperatures of $122 \pm$ $38^{\circ} \mathrm{C}$ for Paris $(n=2), 132 \pm 43^{\circ} \mathrm{C}$ for Murchison $(n=3), 130 \pm 50^{\circ} \mathrm{C}$ for Murray $(n=3), 157$ 
$476 \pm 48^{\circ} \mathrm{C}$ for Cold Bokkeveld $(\mathrm{n}=2)$ and $153^{\circ} \mathrm{C}\left( \pm 47^{\circ} \mathrm{C}\right)$ for Nogoya $(\mathrm{n}=1)$. These 477 temperatures are higher than the predicted range of precipitation temperatures of (i) $\mathrm{CM}$ 478 carbonates estimated from bulk and in situ oxygen isotopic measurements and 'clumped' 479 isotopes $\left(0-110^{\circ} \mathrm{C}\right.$; Clayton and Mayeda, 1984; Benedix et al. 2003; Guo and Eiler, 2007, 480 Verdier-Paoletti et al., 2017) and (ii) cronstedtite deduced from hydrothermal experiments 481 and thermodynamic data (i.e., $50 \leq \mathrm{T} \leq 120^{\circ} \mathrm{C}$; Pignatelli et al. 2013, 2014; Zolotov 2014).

482 These elevated average precipitation temperatures of meteoritic tochilinite indicate that 483 CM carbonates cannot be formed at the same time as meteoritic tochilinite. This result is 484 consistent with petrographic observations that indicate that primary carbonates (i.e., type 1a 485 calcite; Lee et al. 2014) precipitated at the earliest stages of alteration, before their partial or 486 complete replacement by TCIs (Lee et al. 2013; Vacher et al. 2017). Taking together, the 487 formation temperatures and the mineralization sequence of carbonate and tochilinite minerals 488 suggest an increase of the temperature during the duration of aqueous alteration, from $0-70^{\circ} \mathrm{C}$ 489 for carbonate to $120-160^{\circ} \mathrm{C}$ for tochilinite (Fig. 12). Furthermore, the chemical zoning 490 observed in Type-II TCIs (i.e., the Fe- and S-enrichment at the border and the Fe- and Si491 enrichment toward the center; Pignatelli et al. 2016) indicates that cronstedtite may 492 precipitated after tochilinite, due to the decrease of the sulfur activity during the duration of 493 aqueous alteration (Pignatelli at al. 2017). If so, the range of low formation temperatures of 494 cronstedtite implies that this mineral may precipitated during the cooling phase of the CM 495 parent body, between 50 and $120^{\circ} \mathrm{C}$ (Fig. 12). This result is in good agreement with 496 experimental data that demonstrated that the development of crystals of cronstedtite is likely 497 promoted by a temperature decrease during the course of alteration (Pignatelli et al. 2013).

498 Therefore, the $\mathrm{Mg}$ content of tochilinite seems to be a powerful proxy in order estimate 499 the alteration temperature of CM chondrites. However, we note that this correlation is based 500 on a small amount of data and further hydrothermal experiments are needed to better 501 understand the role of the other physiochemical parameters (e.g., pH, W/R ratio, starting 502 assemblage or solution chemistry) in controlling of the Mg content of tochilinite. 
503

504

505

506

507

508

509

510

511

512

513

514

515

516

517

518

519

520

521

522

523

524

525

526

527

528

529

530

531

532

533

534

535

\section{Co-precipitation of tochilinite and cronstedtite in CM chondrites?}

In $\mathrm{CM}$ chondrites, tochilinite has been proposed to precipitate during the first stages of aqueous alteration under very low oxygen fugacity (Browning and Bourcier 1996), neutralalkaline pH (Kozerenko et al. 1996; Peng et al. 2007; Peng and Jing 2014), and at 80-320 $\mathrm{C}$ (Kozerenko et al. 1996, 2001), whereas cronstedtite forms under less reduced conditions than tochilinite due to the presence of $\mathrm{Fe}^{3+}$ (Pignatelli et al. 2014), in circumneutral $\mathrm{pH}$ environments (Pignatelli et al. 2013), and below $120^{\circ} \mathrm{C}$ (Lantenois et al. 2005; Lanson et al. 2012; Pignatelli et al. 2013, 2014) (Fig. 13). Therefore, it has been proposed that CM chondrite alteration conditions changed during alteration, with the initial precipitation of tochilinite followed by the formation of cronstedtite (Pignatelli et al. 2016). However, tochilinite is frequently observed in close association with cronstedtite in Type-II TCIs at both the micron and the nanometer scales (Mackinnon and Zolensky 1984; Haack et al. 2012; Leroux et al. 2015; Pignatelli et al. 2016, 2017). This complex intergrowth indicates that (i) tochilinite and cronstedtite may co-precipitated under similar physicochemical conditions for at least a short time (Palmer and Lauretta 2011; Pignatelli et al. 2016) and/or (ii) cronstedtite could have replaced tochilinite during the course of alteration. Identifying which of these two scenarios prevailed is not an easy task, because the intergrowth between tochilinite and cronstedtite can be attributed to either of these two processes. Nevertheless, because tochilinite and cronstedtite have been formed under similar physicochemical conditions in our experiments (i.e., $80^{\circ} \mathrm{C}$ and $\mathrm{pH} \approx 8$ ), here we explore the possibility that they both could have been formed at the same time.

We did not observe cronstedtite crystals in our S-bearing experiments, though we expected cronstedtite to form in experiment GOIS due to (i) the similar proportion of starting assemblages as the cronstedtite-producing S-free experiment GOI and (ii) the favorable concentration of $\mathrm{Si}$ in the run solutions (Table S2, Fig. 13). This lack of cronstedtite formation may have explained by the final alkalinity of the experiment $(\mathrm{pH}=9.7)$ preventing cronstedtite precipitation (Pignatelli et al. 2015) or the reaction time being too short under the experimental conditions to produce abundant cronstedtite of a high degree of crystallinity compared to longer syntheses (Table 2).

Nonetheless, the occurrence of tochilinite and cronstedtite at $80^{\circ} \mathrm{C}$ in the S-rich and S-free experiments, respectively, suggests that both minerals might form at similar aqueous alteration temperatures. Because the stability field of cronstedtite is expected to diminish with increasing temperature (Pignatelli et al. 2014; Zolotov 2014) and cronstedtite was not 
536 observed in experiments at $\geq 150^{\circ} \mathrm{C}$ (Rivard 2011; Pierron 2011), co-precipitation of 537 tochilinite and cronstedtite implies a restrictive alteration temperature range of $80-120^{\circ} \mathrm{C}$ 538 (Fig. 12). Following the same logic, in our experiments, cronstedtite formed at $\mathrm{pH} \approx 7-8$ and tochilinite at $\mathrm{pH}=\sim 8-11$, consistent with previous results for cronstedtite $(\mathrm{pH}=7.2-7.6$;

540 Pignatelli et al. 2013) and tochilinite ( $\mathrm{pH}=7.3-11.4$; Kozorenko et al. 1996). Thus, co541 precipitation of tochilinite and cronstedtite should indicate a circumneutral environment of $\mathrm{pH}$ $542=7-8$.

543 Quantitative estimation of the redox conditions of tochilinite and cronstedtite co544 precipitation is more problematic because, according to thermodynamic modelling, these two 545 minerals do not share a common $f \mathrm{O}_{2}$ range (Fig. 13; Browning and Bourcier 1996; Dyl et al. 546 2006; Pignatelli et al. 2014). The $f \mathrm{O}_{2}$ of cronstedtite precipitation is well constrained in our 547 experiments due to the limited variation of $\mathrm{Si}$ concentrations in the associated run solutions 548 (i.e., $\mathrm{Si} \approx 4 \mathrm{mM}$, Table S2), implying $f \mathrm{O}_{2}$ conditions in the range $\log f \mathrm{O}_{2}=-62$ to -58 at $80^{\circ} \mathrm{C}$ 549 (Figs. 10 and 13). However, we cannot directly estimate the $f_{2}$ for our synthetic tochilinite 550 due to the limited available information on its stability. Browning and Bourcier (1996) 551 showed that the stability of Fe-rich tochilinite implies extremely reducing conditions 552 compared to cronstedtite, i.e., $\log f \mathrm{O}_{2}=-91$ to -85 , though this range of oxygen fugacity is 553 relevant at $0^{\circ} \mathrm{C}$ (Fujiya et al. 2015), too cold for the formation of meteoritic tochilinite. With 554 increasing temperature, the stability fields of Fe-O-S minerals move toward higher $f \mathrm{O}_{2}$ and $f \mathrm{~S}_{2}$ 555 (Holland 1959), as demonstrated in Fig. 13. Thus, above $0^{\circ} \mathrm{C}$, the $\mathrm{fO}_{2}$ of tochilinite 556 precipitation should be above the values estimated by Browning and Bourcier (1996). This 557 interpretation is supported by the high $\mathrm{Fe}^{3+} / \Sigma \mathrm{Fe}$ ratio measured in CM Paris Fe-rich tochilinite 558 (i.e., 8-15\%; Pignatelli et al. 2017), suggesting that precipitation of tochilinite may have 559 occurred under sufficiently oxidizing conditions to incorporate $\mathrm{Fe}^{3+}$ into its mineral structure. 560 Consequently, $\mathrm{CM}$ tochilinite formation at $120-160{ }^{\circ} \mathrm{C}$ (Fig. 13) does not require such 561 extremely reduced conditions as at $0^{\circ} \mathrm{C}$ (Browning and Bourcier 1996). According to our S562 bearing experiments, the presence of a magnetite-like phase around iron metal grains suggests $563 \log f \mathrm{O}_{2}$ values between -73 and -60 at $80^{\circ} \mathrm{C}$ (Fig. 13). 
We have performed low temperature experiments using starting mineral assemblages (reduced glass, San Carlos olivine, metallic iron) close to those observed in the least altered $\mathrm{CM}$ chondrites to better understand the alteration conditions of hydrated asteroids. Triangular cronstedtite crystals formed only in S-free circumneutral conditions $(\mathrm{pH}=7-8)$ with the highest $\mathrm{Fe}$ content studied $\left(\mathrm{Fe}_{\mathrm{tot}} / \mathrm{Si}=2.7\right)$, suggesting that chondritic cronstedtite crystals likely formed by reaction of matrix amorphous silicates, Fe-Ni metal beads, and water. For the first time, we have synthesized tochilinite similar to meteoritic tochilinite under conditions analogous to $\mathrm{CM}$ chondrite alteration. Iron-rich tochilinite systematically surrounds iron metal grains in all our S-bearing experiments, regardless of the starting mineral assemblage and the proportion of metallic iron, indicating that chondritic tochilinite likely formed from the alteration of Fe-Ni metal beads in a S-bearing alkaline environment at low temperature (i.e., $<160^{\circ} \mathrm{C}$ ).

As both tochilinite and cronstedtite precipitated at $80^{\circ} \mathrm{C}$ in our experiments, these minerals may have formed at similar aqueous alteration temperatures in CM chondrites. Because cronstedtite stability field is expected to diminish with increasing temperature, an expected co-precipitation of tochilinite and cronstedtite requires restrictive alteration conditions: $80-120^{\circ} \mathrm{C}, \mathrm{pH}=7-8$, and more oxidized conditions $\left(\log f \mathrm{O}_{2} \approx-65\right.$ to -60$)$ than previously estimated for tochilinite. Comparison of our results to other experimental approaches revealed a positive correlation between the $\mathrm{Mg}$ content in the hydroxide layer of synthetic tochilinite and temperature. Based on this correlation, we estimated the mean precipitation temperatures of meteoritic tochilinite to be $\sim 120^{\circ} \mathrm{C}$ for Paris, $\sim 130^{\circ} \mathrm{C}$ for Murchison and Murray, $\sim 150^{\circ} \mathrm{C}$ for Nogoya, and $\sim 160^{\circ} \mathrm{C}$ for Cold Bokkeveld.

Acknowledgments - We are very grateful to Jaafar Ghanbaja and Sylvie Migot for assistance with TEM characterization. We thank Hervé Marmier, Géraldine Kitzinger, and the SARM team for their technical support for solution analyses. Maxime Clément is thanked for his support in the reduction of the synthetic glass with the sealed evacuated silica glass tubes. We are grateful to Pierrick Durant for his assistance with XRD analyses. We are also grateful to Conel Alexander for very constructive review and helpful comments. Isabella Pignatelli is thanked for helpful discussions. Roger Hewins, Martin Lee and associated editor Mike 
1'Agence Nationale de la Recherche through grant ANR-14-CE33-0002-01 SAPINS (PI Yves Marrocchi) and OTELo. This is CRPG contribution \#2676.

\section{REFERENCES}

Barber D. J. 1981. Matrix phyllosilicates and associated minerals in C2M carbonaceous chondrites. Geochimica et Cosmochimica Acta 45:945-970.

Bailey S. W. 1988. Odinite, a new dioctahedral-trioctahedral $\mathrm{Fe}^{3+}$-rich 1:1 clay mineral. Clay Mineral 23:237-247.

Bunch T. E. and Chang S. 1980. Carbonaceous chondrites-II. Carbonaceous chondrite phyllosilicates and light element geochemistry as indicators of parent body processes and surface conditions. Geochimica et Cosmochimica Acta 44:1543-1577.

Benedix G., Leshin L., Farquhar J., Jackson T., and Thiemens M. 2003. Carbonates in CM2 chondrites: constraints on alteration conditions from oxygen isotopic compositions and petrographic observations. Geochimica et Cosmochimica Acta 67:1577-1588.

Bradley, J. P. 1994. Chemically Anomalous, Preaccretionally Irradiated Grains in Interplanetary Dust form Comets. Science 265:925-929.

Brearley A. J. 2006. The action of water. In Meteorites and the early solar system II, edited by Lauretta D. S. and McSween H. Y. Tucson, Arizona: The University of Arizona Press. pp. 587-624.

Brindley, G.W. 1982. Chemical compositions of berthierines - a review. Clays Clay Miner. 30:153-155.

Browning L. B. and Bourcier W. L. 1996. Tochilinite: A sensitive indicator of alteration conditions on the CM asteroidal parent body. Proceedings, 44th Lunar and Planetary Science Conference. pp. 171-172.

Chistyakova N.I., Rusakov V.S., Gubaidulina T.V., and Kozerenko S.V. 2006. Investigations of sulfide minerals with layered structure by Mössbauer spectroscopy methods. ICAME 2005 66:613-617.

Clark B. E., Ziffer J., Nesvorny D., Campins H., Rivkin A. S., Hiroi T., Barucci M. A., Fulchignoni M., Binzel R. P., Fornasier S., DeMeo F., Ockert-Bell M. E., Licandro J., and Mothé-Diniz T. 2010. Spectroscopy of B-type asteroids: Subgroups and meteorite analogs. Journal of Geophysical Research Planets 115:1-22.

Clayton R. N. and Mayeda T. K. 1984. The oxygen isotope record in Murchison and other carbonaceous chondrites. Earth and Planetary Science Letter 67:151-161.

Cloutis E. A., Hiroi T., Gaffey M. J., Alexander C. M. O’D., and Mann P. 2011. Spectral reflectance properties of carbonaceous chondrites: 1. CI chondrites. Icarus 212:180209.

Dargent M., Truche L., Dubessy J., Bessaque G., and Marmier H. 2015. Reduction Kinetics 
of Aqueous U(VI) in Acidic Chloride Brines to Uraninite by Methane, Hydrogen or CGraphite under Hydrothermal Conditions: Implications for the Genesis of Unconformity-Related Uranium Ore Deposits. Geochimica et Cosmochimica Acta 167:11-26.

Davoisne C., Djouadi Z., Leroux H., d'Hendecourt L., Jones A., and Deboffle D. 2006. The origin of GEMS in IDPs as deduced from microstructural evolution of amorphous silicates with annealing. Astronomy \& Astrophysics 448:L1-L4.

Declercq J., Diedrich T., Perrot M., Gislason S. R., and Oelkers E. H. 2013. Experimental determination of rhyolitic glass disso- lution rates at $40-200^{\circ} \mathrm{C}$ and $2<\mathrm{pH}<10.1$. Geochimica et Cosmochimica Acta 100:251-263.

Dyl K.A., Manning C.E., and Young E.D. 2006. Modelling aqueous alteration of CM carbonaceous chondrites: implications for cronstedtite formation by water-rock reaction. (abstract \#2060). 37th Lunar and Planetary Science Conference.

Fuchs L. H., Olsen E., and Jensen K. J. 1973. Mineralogy, mineral-chemistry, and composition of the Murchison (C2) meteorite. Smithsonian Contributions to the Earth Sciences 10:1-39.

Fujiya W., Sugiura N., Marrocchi Y., Takahata N., Hoppe P., Shirai K., Sano Y., and Hiyagon H. 2015. Comprehensive study of carbon and oxygen isotopic compositions, trace element abundances, and cathodoluminescence intensities of calcite in the Murchison CM chondrite. Geochimica et Cosmochimica Acta 161:101-117.

Gubaidulina T. V., Chistyakova N. I., and Rusakov V. S. 2007. Mössbauer study of layered iron hydroxysulfides: Tochilinite and valleriite. Bulletin of the Russian Academy of Sciences: Physics 71:1269-1272.

Guggenheim S., Bailey S. W., Eggleton R. A., and Wilkes P. 1982. Structural aspects of greenalite and related minerals. The Canadian Mineralogist 20:1-18.

Haack H., Grau T., Bischoff A., Horstmann M., Wasson J., Sorensen A., Laubenstein M., Ott U., Palme H., Gellissen M., Greenwood R. C., Pearson V. K., Franchi I. A., Gabelica Z., and Schmitt-Kopplin P. 2012. Maribo-A new CM fall from Denmark. Meteoritics \& Planetary Science 47:30-50.

Hanowski N. P. and Brearley A. J. 2001. Aqueous alteration of chondrules in the CM carbonaceous chondrite, Allan Hills 81002: Implications for parent body alteration. Geochimica et Cosmochimica Acta 65:495-518.

Hewins R. H., Bourot-Denise M., Zanda B., Leroux H., Barrat J.-A., Humayun M., Göpel C., Greenwood R. C., Franchi I. A., Pont S., Lorand J.-P., Cournède C., Gattacceca J., Rochette P., Kuga M., Marrocchi Y., and Marty B. 2014. The Paris meteorite, the least altered CM chondrite so far. Geochimica et Cosmochimica Acta 124:190-222.

Holland H. D. 1959. Stability relations among the oxides, sulfides, sulfates and carbonates of ore and gangue metals, [Part] 1 of Some applications of thermochemical data to problems of ore deposits. Economic Geology 54:184-233.

Howard K. T., Alexander C. M. O’D., Schrader D. L., and Dyl K. A. 2015. Classification of 
hydrous meteorites (CR, CM and $\mathrm{C} 2$ ungrouped) by phyllosilicate fraction: PSD-XRD modal mineralogy and planetesimal environments. Geochimica et Cosmochimica Acta 149:206-222.

Howard K. T., Benedix G. K., Bland P. A. and Cressey G. 2011. Modal mineralogy of CM chondrites by X-ray diffraction (PSD-XRD): Part 2. Degree, nature and settings of aqueous alteration. Geochimica et Cosmochimica Acta 75:2735-2751.

Howard K. T., Benedix G. K., Bland P. A. and Cressey G. 2009. Modal mineralogy of CM2 chondrites by PSD-XRD: Part 1. Total phyllosilicate abundance and the degree of aqueous alteration. Geochimica et Cosmochimica Acta 73:4576-4589.

Hybler J., Petř́iček V., Ďurovič S., and Smrčok Ĺ. 2000. Refinement of the Crystal Structure of Cronstedtite-1T. Clays and Clay Minerals 48:331-338.

Jarosewich E. 1990. Chemical analyses of meteorites: a compilation of stony and iron meteorite analyses. Meteoritics 25:323-337.

Kakos G. A., Turney T. W., and Williams T. B. 1994. Synthesis and structure of tochilinite: A layered metal hydroxide/sulfide composite. Journal of Solid State Chemistry 108:102111.

Keller L. P. and Messenger S. 2011. On the origins of GEMS grains. Geochimica et Cosmochimica Acta 75:5336-5365.

Kogure, T., Hybler, J., and Yoshida, H. 2002. Coexistence of two polytypic groups in cronstedtite from Lostwithiel England. Clays and Clay Minerals 50:504-513.

Kozerenko S.V., Fadeev V.V., Organova N.I., Chstyakova N.I., Kolpakova N.N., and Senin V.G. 2001. Synthesis, formation conditions and crystallochemistry of tochilinites iron, magnesium and sodium hydroxide-sulfides. Experiment in Geosciences 10:5758 .

Kozerenko S. V., Organova N. J., Fadeev V. V., Magazina L.O., Kolpakova N. N., and Kopneva L. A. 1996. Tochilinite produced in laboratory. Proceedings, 27th Lunar and Planetary Science Conference. pp. 695-696.

Lanson, B., Lantenois, S., Van Aken, P.A., Bauer, A., and Plançon, A. 2012. Experimental investigation of smectite interaction with metal iron at $80^{\circ} \mathrm{C}$ : structural characterization of newly formed Fe-rich phyllosilicates. American Mineralogist 97:864-871.

Lantenois, S., Lanson, B., Muller, F., Bauer, A., Jullien, M., and Plançon, A. 2005. Experimental study of smectite interaction with metal Fe at low temperature: 1. Smectite destabilization. Clays and Clay Minerals 53:597-612.

Lee M. R., Lindgren P. and Sofe M. R. 2014. Aragonite, breunnerite, calcite and dolomite in the CM carboanceous chondrites: High fidelity recorders of progressive parent body aqueous alteration. Geochimica et Cosmochimica Acta 144:126-156.

Lee M. R., Sofe M. R., Lindgren P., Starkey N. A. and Franchi I. A. 2013. The oxygen isotope evolution of parent body aqueous solutions as recorded by multiple carbonate 
generations in the Lonewolf Nunatak 94101 CM2 carbonaceous chondrite. Geochimica et Cosmochimica Acta 121:452-466.

Lee M. R. and Ellen R. 2008. Aragonite in the Murray (CM2) carbonaceous chondrite: implications for parent body compaction and aqueous alteration. Meteoritics \& Planetary Science 43:1219-1231.

Leroux H., Cuvillier P., Zanda B., and Hewins R. H. 2015. GEMS-like material in the matrix of the Paris meteorite and the early stages of alteration of CM chondrites. Geochimica et Cosmochimica Acta 170:247-265.

MacKinnon I. D. R. and Zolensky M. E. 1984. Proposed structures for poorly characterized phases in C2M carbonaceous chondrite matrix. Nature 309:240-242.

Marrocchi Y., Gounelle M., Blanchard I., Caste F. and Kearsley A. T. (2014) The Paris CM chondrite: Secondary minerals and asteroidal processing. Meteorit. Planet. Sci. 49, 1232-1249.

Marrocchi Y., Bekaert D. V., and Piani L. 2018. Origin and abundance of water in carbonaceous asteroids. Earth and Planetary Science Letter 482:23-32.

McAlister, J.A. and Kettler, R.M. 2008. Metastable equilibria among dicarboxylic acids and the oxidation state during aqueous alteration on the CM2 chondrite parent body. Geochimica et Cosmochimica Acta 72:233-241.

Mizutani T., Fukushima Y., Okada A., Kamigaito, O., and Kobayashi T. 1991. Synthesis of 1:1 and 2:1 iron phyllosilicates and characterization of their iron state by Mössbauer spectroscopy. Clays and Clay Minerals 39:381-386.

Moroz L. V., Kozerenko S. V. and Fadeev V. V. 1997. The reflectance spectrum of synthetic tochilinite. Proceedings, 28th Lunar and Planetary Science Conference. pp. 983-984.

Nakamura T. and Nakamuta Y. 1996. X-ray study of PCP from the Murchison CM carbonaceous chondrite. Proceeding of the NIPR Symposium on Antarctic Meteorites 9:37-50.

Organova N. I., Gorshkov A. I., Dikov Yu. P., Kul'bachinskiy V. A., Laputina I. P., Sivtsov A. V., Sluzhenikin S. F., and Ponomarenko A. I. 1988. The new data on tochilinite. International Geology Review 6:84-98.

Organova N. I., Drits V. A., and Dmitrik A. L. 1973. Structural study of tochilinite. Part I. The isometric variety. Soviet Physics - Crystallography 17:667-671.

Organova N. I., Genkin A. D., Drits V. A., Dmitrik A. L. and Kuzmina O. V. 1971. Tochilinite: A new sulfide hydroxide of iron and magnesium. Zapiski Vses Mineralogiscogo Obschestva 4:477-487.

Palmer E. E. and Lauretta D. S. 2011. Aqueous alteration o kamacite in CM chondrites. Meteoritics \& Planetary Science 46:1587-1607.

Peng Y., Xu L., Xi G., Zhong C., Lu J., Meng Z., Li G., Zhang S., Zhang G., and Qian Y. 2007. An experimental study on the hydrothermal preparation of tochilinite nanotubes 
and tochilinite serpentine-intergrowth nanotubes from metal particles. Geochimica et Cosmochimica Acta 71:2858-2875.

Peng Y. and Jing Y. 2014. Hydrothermal preparation of analogous matrix materials of carbonaceous chondrites from metal alloy particles. Meteoritics \& Planetary Science 402:252-262.

Pierron O. 2011. Interactions eau-fer-argilite: Rôle des paramètres Liquide/Roche, Fer/Argilite, Température sur la nature des phases minérales. Ph.D. thesis, Henri Poincaré University, Nancy, France.

Pekov I. V., Sereda E. V., Polekhovsky Yu. S., Britvin S. N., Chukanov N. V., Yapaskurt V. O., and Bryzgalov I. A. 2013. Ferrotochilinite, $6 \mathrm{FeS} \cdot 5 \mathrm{Fe}(\mathrm{OH})_{2}$, a new mineral from the Oktyabr'sky deposit, Noril'sk district, Siberia, Russia. Geology of Ore Deposits 55:567-574.

Pignatelli I., Mugnaioli E., and Marrocchi Y. 2018. Cronstedtite polytypes in the Paris meteorite. European Journal Mineralogy 30:349-354.

Pignatelli I., Marrocchi Y., Mugnaioli E., Bourdelle F., and Gounelle M. 2017. Mineralogical, crystallographic and redox features of the earliest stages of fluid alteration in CM chondrites. Geochimica et Cosmochimica Acta 209:106-122.

Pignatelli I., Marrocchi Y., Vacher L. G., Delon R., and Gounelle M. 2016. Multiple precursors of secondary mineralogical assemblages in CM chondrites. Meteoritics \& Planetary Science 51:785-805.

Pignatelli I., Vacher L. G., and Marrocchi Y. 2015. Hydrothermal preparation of analogous matrix minerals of $\mathrm{CM}$ carbonaceous chondrites from metal alloy particles" by Y. Peng and Y.Jing [Earth Planet. Sci. Lett. 408 (2014) 252-262]. Earth and Planetary Science Letter 428:307-309.

Pignatelli I., Bourdelle F., Bartier D., Mosser-Ruck R., Truche L., Mugnaioli E., and Michau N. 2014. Iron-clay interactions: detailed study of the mineralogical transformation of claystone with emphasis on the formation of iron-rich T-O phyllosilicates in a step-bystep cooling experiment from $90^{\circ} \mathrm{C}$ to $40^{\circ} \mathrm{C}$. Chemical Geology 387:1-11.

Pignatelli I., Mugnaioli E., Hybler J., Mosser-Ruck R., Cathelineau M., and Michau N. 2013. A multi-technique characterization of cronstedtite synthesized by iron-clay interaction in a step-by-step cooling procedure. Clays and Clay Minerals 61:277-289.

Ramdohr P. 1963. The opaque minerals in stony meteorites. Journal of Geophysical Research 68:2011-2036.

Rivard, C. 2011. Contribution à l'étude de la stabilité des minéraux constitutifs de l'argilite du Callovo-Oxfordien en présence de fer à $90^{\circ} \mathrm{C}$. Ph.D. thesis, Henri Poincaré University, Nancy, France.

Rubin A. E., Trigo-Rodríguez J. M., Huber H., and Wasson J. T. 2007. Progressive aqueous alteration of CM carbonaceous chondrites. Geochimica et Cosmochimica Acta 71:2361-2382. 
Schulte, M. and Schock, E. 2004. Coupled organic synthesis and mineral alteration on the meteorite parent bodies. Earth and Planetary Science Letter 39:1577-1590.

Skynner, B. J. and Luce, D. 1971. Solid Solutions of the type (Ca,Mg,Mn,Fe)S and their use as geothermometers for the enstatite chondrites. American Mineralogist 56:12691297.

Tomeoka K. and Buseck P. R. 1985. Indicators of aqueous alteration in CM carbonaceous chondrites: Microtextures of a layered mineral containing $\mathrm{Fe}, \mathrm{S}, \mathrm{O}$ and $\mathrm{Ni}$. Geochimica et Cosmochimica Acta 49:2149-2163.

Vacher L. G., Marrocchi Y., Villeneuve J., Verdier-Paoletti M. J., and Gounelle M. 2017. Petrographic and $\mathrm{C} \& \mathrm{O}$ isotopic characteristics of the earliest stages of aqueous alteration of CM chondrites. Geochimica et Cosmochimica Acta 213:271-290.

Velbel M. A. 2014. Stoichiometric reactions describing serpentinization of anhydrous primary silicates: a critical appraisal, with application to aqueous alteration of chondrule silicates in CM carbonaceous chondrites. Clays and Clay Minerals 62:126-136.

Verdier-Paoletti M. J., Marrocchi Y., Avice G., Roskosz M., Gurenko A. and Gounelle M. (2017) Oxygen isotope constraints on the alteration temperatures of CM chondrites. Earth Planet. Sci. Lett. 458, 273-281.

Vienna, J. D., James J. N., Joseph V. R., and Sebastien N. K. 2018. Impacts of glass composition, $\mathrm{pH}$, and temperature on glass forward dissolution rate. Npj Materials Degradation 2:22.

Zolensky M. E., Mittlefehldt D. W., Lipschutz M. E., Wang M.-S., Clayton R. N., Mayeda T. K., Grady M. M., Pillinger C., and B D. 1997. CM chondrites exhibit the complete petrologic range from type 2 to 1. Geochimica et Cosmochimica Acta 61:5099-5115.

Zolensky M. E. and Mackinnon I. D. R. 1986. Microstructures of cylindrical tochilinites. American Mineralogist 71:1201-1209.

Zolensky M. E., Barett R. and Browning L. 1993. Mineralogy and composition of matrix and chondrule rims in carbonaceous chondrites. Geochimica et Cosmochimica Acta $57: 3123-3148$.

Zolotov M. Y. 2014. Formation of brucite and cronstedtite-bearing mineral assemblages on Ceres. Icarus 228:13-26. 
Fig. 1. Synthetic GEMS-like glass preparation. a) Schematic representation of the sealed evacuated silica tube method used in this study to reduce our synthetic glass. At time $t_{1}$, the silica glass tube was connected to a vacuum pump to evacuate the atmosphere inside the tube. When the pressure reached $2 \times 10^{-2}$ mbar (time $t_{2}$ ), the silica glass was melted using a torch to seal the tube without breaking the vacuum. b) and c) BSE images of the synthetic GEMS-like material after three days of reduction at $1000^{\circ} \mathrm{C}$.

Fig. 2. Overview of the anoxic hydrothermal experiments. a) Initial mixing proportions of the solid starting products and their respective bulk Fe/Si ratio. b) Schematic representation of the loaded autoclaves for the two sets of experiments and summary of the initial parameters.

Fig. 3. Run products from the circumneutral S-free experiments. a) BSE image of run products from experiment GOI-2, showing the occurrence of iron oxide grains of a few tens of microns. b) TEM imaging of a Fe-Si-rich phase located around an iron metal grain in experiment G-1. c) Chemical compositions (wt.\%) of the synthetic assemblages produced in experiments GOI-1 and GOI-2 plotted in a Fe-Mg-Si ternary diagram (see Table S1 for details). White diamonds represent the composition of meteoritic cronstedtite from the Paris CM chondrite (Pignatelli et al. 2018). Black circles represent the ideal chemical compositions of berthierine ('Be'; Brindley 1982), cronstedtite ('Cr'; Hybler et al. 2000; Pignatelli et al. 2013), greenalite ('Gr'; Guggenheim et al. 1982), kamacite ('Ka'), and odinite ('Od'; Bailey 1988).

845

Fig. 4. TEM images and SAED patterns of run products from neutral S-free experiment GOI2. a) An aggregate of four cronstedtite crystals. b) A single cronstedtite crystal in direct contact with fibrous Fe-rich phyllosilicate. c) and d) TEM image and corresponding SAED pattern along the [001] zone axis of a synthetic cronstedtite. e) and f) TEM image and corresponding SAED pattern along the [010] zone axis of another cronstedtite.

Fig. 5. Evolution of solution chemistry during neutral S-free experiments a) G, b) GO, and c) GOI. Si (magenta), Ca (green), Mg (purple), and Fe (orange) concentrations in the run solutions are shown as a function of elapsed time (error bars are 10\%). Al concentrations (not shown) remained low and are reported in Table $\mathbf{S 2}$. d) $\mathrm{pH}$ of the solutions measured at $25^{\circ} \mathrm{C}$ 
856

in experiments G (black open squares and solid line), GO (black solid squares and dashed 858

859 line), and GOI (gray solid squares and line) shown as a function of elapsed time.

Fig. 6. Run products from alkaline S-bearing experiments. a) and b) BSE images of iron metal beads surrounded by three layers of newly precipitated assemblages in experiment GOS- 1 . These phases show different textures: (i) an inner compact layer, (ii) an intermediate acicular layer, and (iii) an outer fibrous layer of variable thickness. c) Chemical compositions (wt.\%) of the synthetic assemblages produced in experiments $\mathrm{G}-\mathrm{S}$ and GO-S plotted in a $\mathrm{Fe}-\mathrm{S}-\mathrm{Si}$ ternary diagram (see Table S3 for details). Black circles represent the ideal chemical compositions of cronstedtite ('Cr'; Hybler et al. 2000; Pignatelli et al. 2013), ferrotochilinite ('Fe-To'; Pekov et al. 2013), greenalite ('Gr'; Guggenheim et al. 1982), kamacite ('Ka), and Mg-tochilinite ('Mg-To'; Organova et al. 1971).

Fig. 7. TEM characterization of secondary iron oxide layers around iron metal grains in alkaline S-bearing experiments. a) An iron metal grain from the FIB-produced cross section of samples from experiment GS-2, surrounded by three layers $\left(Z_{1}, Z_{2}\right.$, and $\left.Z_{3}\right)$ of secondary assemblages. The white solid line in (a) represents the location of the TEM chemical profile in (e). b) to d) TEM-EDS maps of Si, Fe, and $\mathrm{S}$ distributions in the same area shown in (a). e) TEM chemical profile of Fe, O, S, and Si concentrations corresponding to the white solid line in (a).

Fig. 8. TEM images and SAED patterns of secondary acicular tochilinite around iron metal grains. a) TEM image of the GOS-2 FIB-produced cross section. B) TEM image of the products of the S-bearing experiment around an iron metal bead. c) TEM image of the Fe-Srich acicular layer from the GS-2 FIB-produced cross section. d) SAED pattern collected from the acicular mineral displayed in (c) showing broad rings of varying intensity that are consistent with natural tochilinite (Organova et al. 1973; Pekov et al. 2013). e) HRTEM image of a acicular tochilinite. f) SAED pattern of tochilinite along the $\mathrm{c}^{*}$ axis showing the strong (002) diffraction spots of tochilinite.

Fig. 9. Evolution of solution chemistry during alkaline S-bearing experiments a) GS, b) GOS, and c) GOIS. Si (magenta) and Ca (green) concentrations of the solutions are shown as a function of elapsed time (errors are 10\%). $\mathrm{Mg}, \mathrm{Al}$, and $\mathrm{Fe}$ concentrations (not shown) remained very low and are reported in Table 2. d) $\mathrm{pH}$ of solutions measured at $25^{\circ} \mathrm{C}$ in 
890

891

892

893

894

895

896

897

898

899

900

901

902

903

904

905

906

907

908

909

910

911

912

913

914 Fig. 13. $\log f \mathrm{O}_{2}-\log f \mathrm{~S}_{2}$ diagram of the Fe-O-S system at $80^{\circ} \mathrm{C}$ (solid line) and $25^{\circ} \mathrm{C}$ (dotted

915 line) demonstrating the co-stability field of tochilinite and cronstedtite, modified after Holland

916 (1959). The stability field of tochilinite at $0^{\circ} \mathrm{C}$ is from Browning and Bourcier (1996).

experiments GS (black open squares and solid line), GOS (black solid squares and dashed line), and GOIS (grey solid squares and solid line) shown as a function of elapsed time.

Fig. 10. The stability fields of cronstedtite, greenalite, hematite, and magnetite in $\log \left[\mathrm{Si}_{(\mathrm{aq})}\right]$ vs $f\left(\mathrm{O}_{2}\right)$ phase diagrams at $80^{\circ} \mathrm{C}$ (solid black line and blue shaded field), $100^{\circ} \mathrm{C}$, and $150^{\circ} \mathrm{C}$ (dotted lines) from Pignatelli et al. 2014. The vertical dashed black line corresponds to the Si concentration measured in the run solution of S-free experiment GOI and the red shaded area represents the range of $\mathrm{Si}$ concentrations measured in the solutions of S-bearing experiment GOIS.

Fig. 11. Synthesis temperature as a function of $\mathrm{Mg}$ content $(\mathrm{nMg})$ in synthetic tochilinite from this study (red circle) and literature (black circles) (Table S4; Kakos et al. 1994; Kozerenko et al. 1996, 2001; Chistyakova et al. 2006; Peng and Jing 2014). The blue shaded area represents the $\mathrm{nMg}$ values of meteoritic tochilinite (Palmer and Lauretta 2011; Pignatelli et al. 2017) and the associated formation temperatures based on the regression equation $T=175.9( \pm 44.6) \times$ $\mathrm{nMg}+100.4( \pm 17.3)$

Fig. 12. Schematic representation of the expected of ${ }^{26} \mathrm{Al}$ temperature profile of $\mathrm{CM}$ chondrite parent body as function of time. The range of temperature formation of calcite $\left(0-70^{\circ} \mathrm{C}\right.$, green rectangle) and cronstedtite $\left(50-120^{\circ} \mathrm{C}\right.$, blue rectangle) have been taken from the literature (calcite: Clayton and Mayeda 1984, Benedix et al. 2003; Guo and Eiler 2007; cronstedtite: Pignatelli et al. 2013, 2014; Zolotov 2014). Formation age of calcite from Fujiya et al. 2012 is given as indication. 
918

919

920

921

922

923

\section{FIGURES}
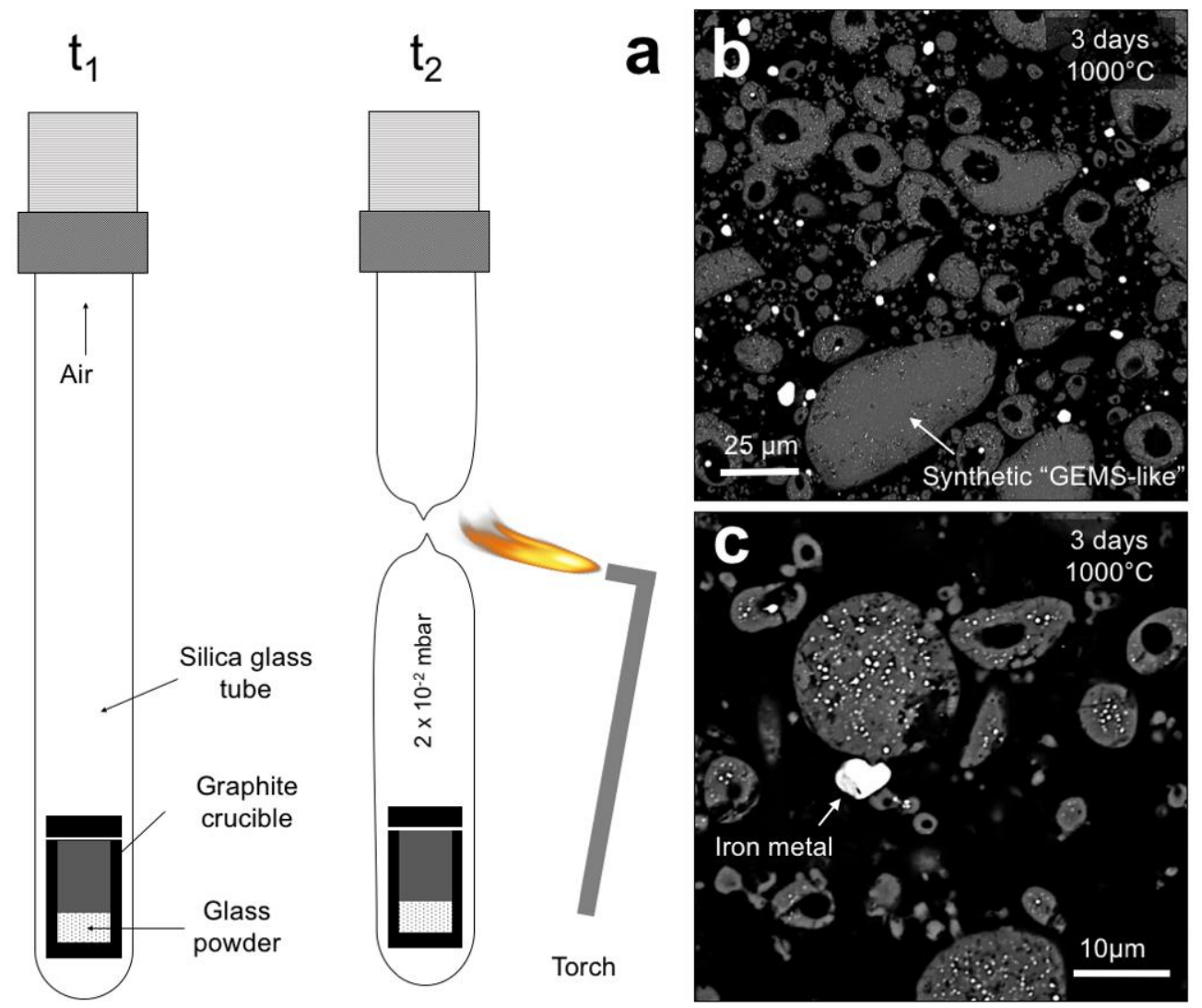

Figure 1 


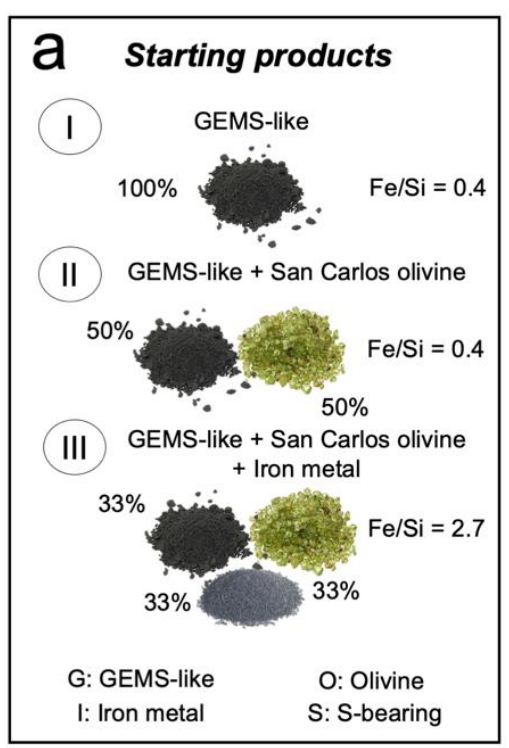

924

925

926 b

S-free experiments

S-bearing experiments

$+\mathrm{Na}_{2} \mathrm{~S}=10 \mathrm{mM}$

$\mathrm{T}^{\circ} \mathrm{C}=80^{\circ} \mathrm{C}$

$W / R=10$

$\left[\mathrm{O}_{2}\right]<1 \mathrm{ppm}$

$30 \& 60$ days

$10 \mathrm{~mL}$ of MilliQ-water $\mathrm{NaCl}=2.4 \mathrm{mM}$ $\mathrm{CaCl}_{2}=0.4 \mathrm{mM}$ $\mathrm{MgCl}_{2}=0.4 \mathrm{mM}$

$1 \mathrm{~g}$ of starting products

$\mathrm{pH}=11.5$

Figure 2 


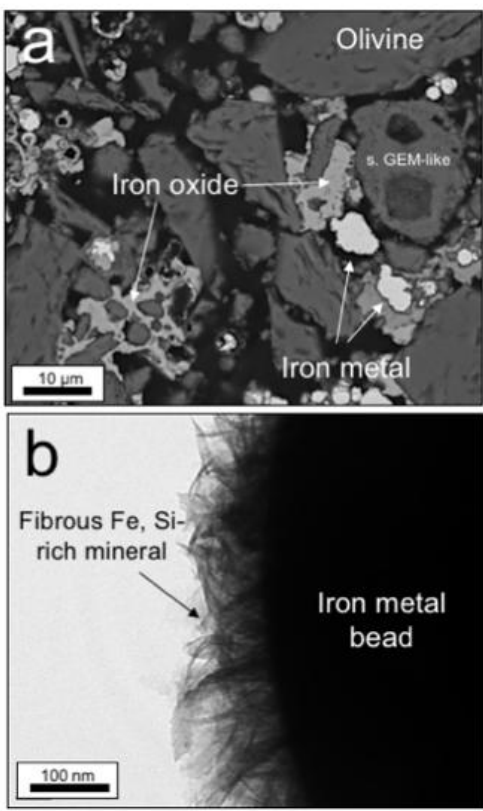

928

929

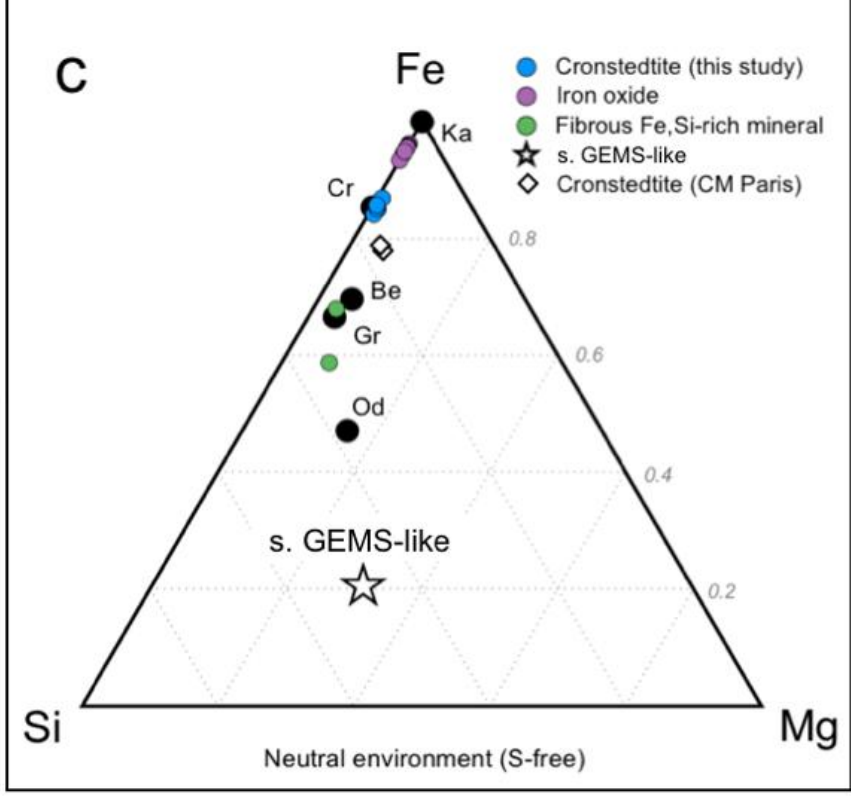

Figure 3 


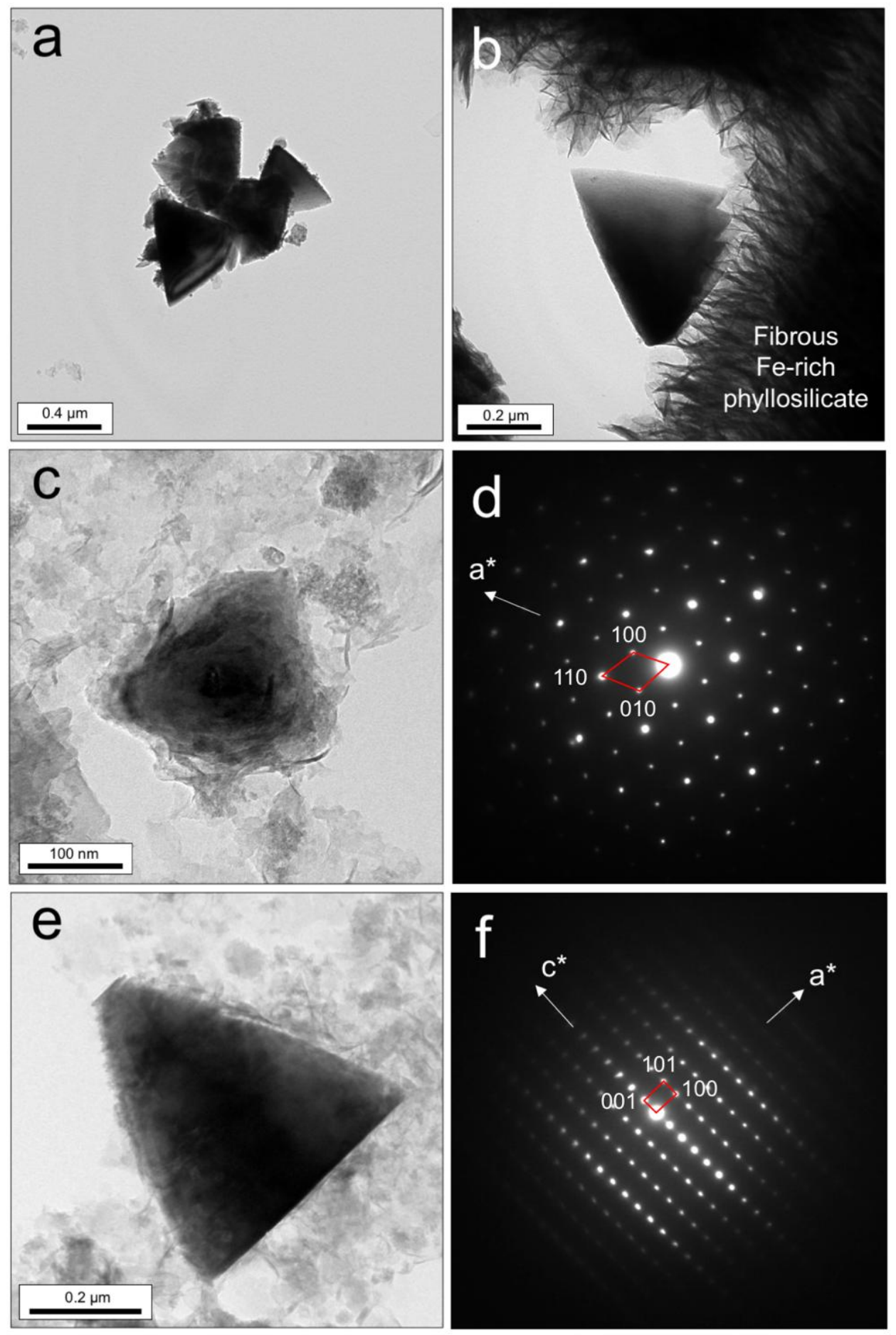

Figure 4 


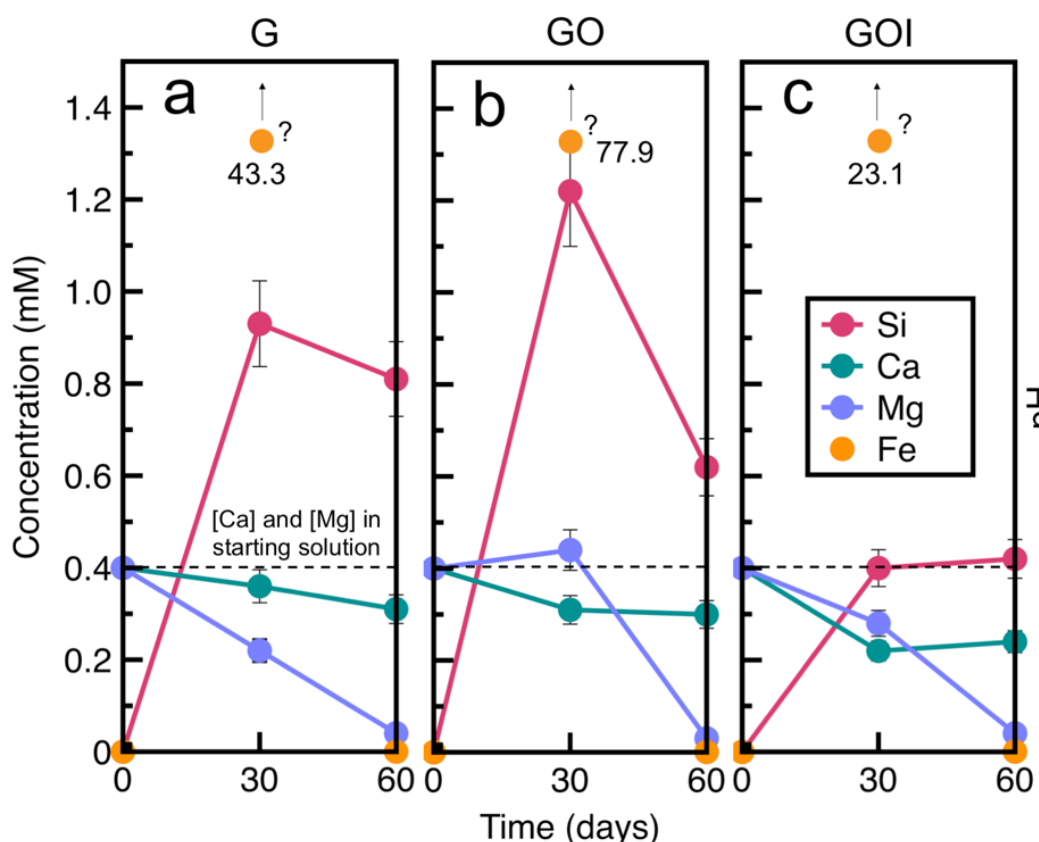

933

934

Figure 5

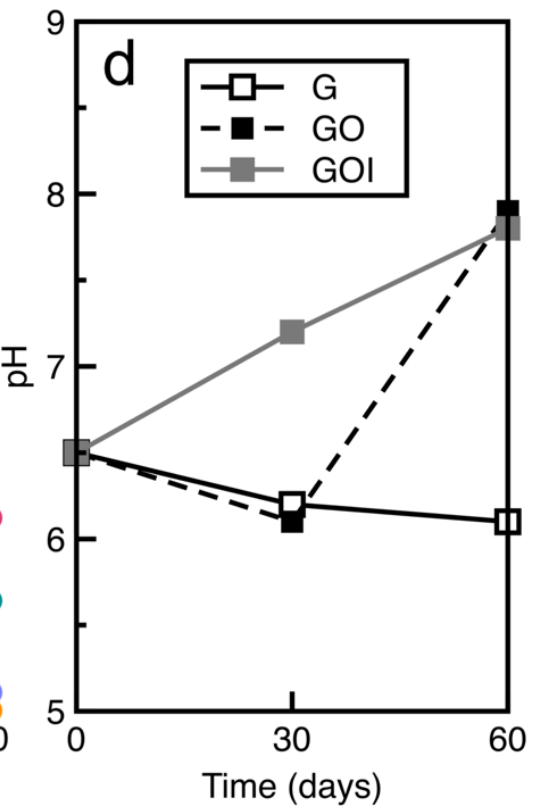

935

936 

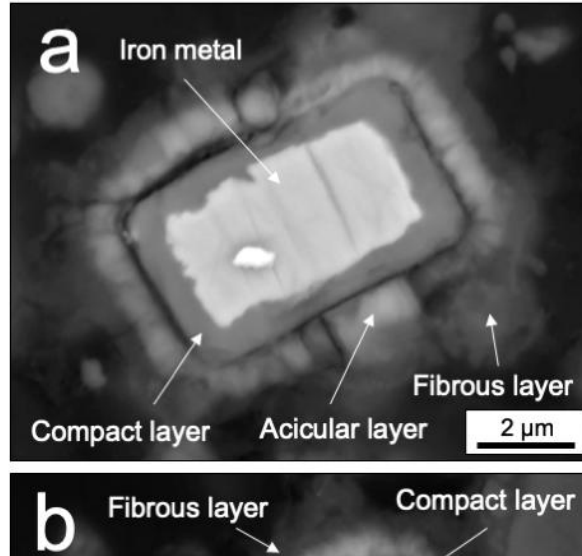

Iron metal

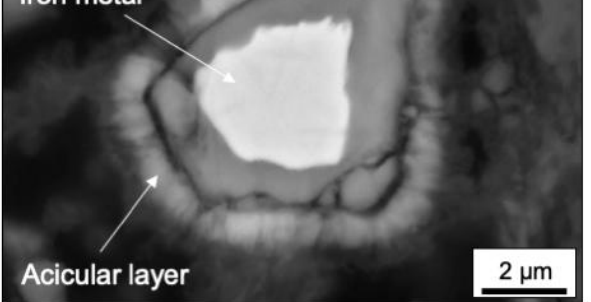

C

- Tochilinite

Fe-rich layer

Fe,Si-rich layer

$\mathrm{Si}$

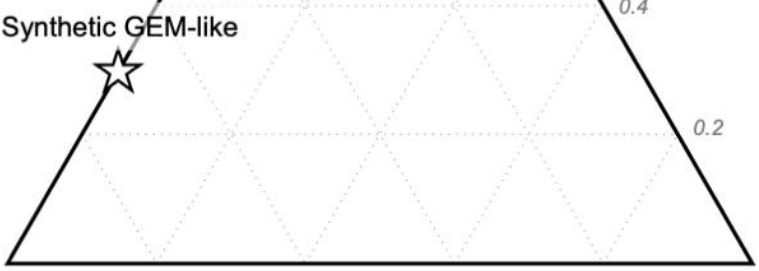

Alkaline environment (S-rich)

Figure 6 


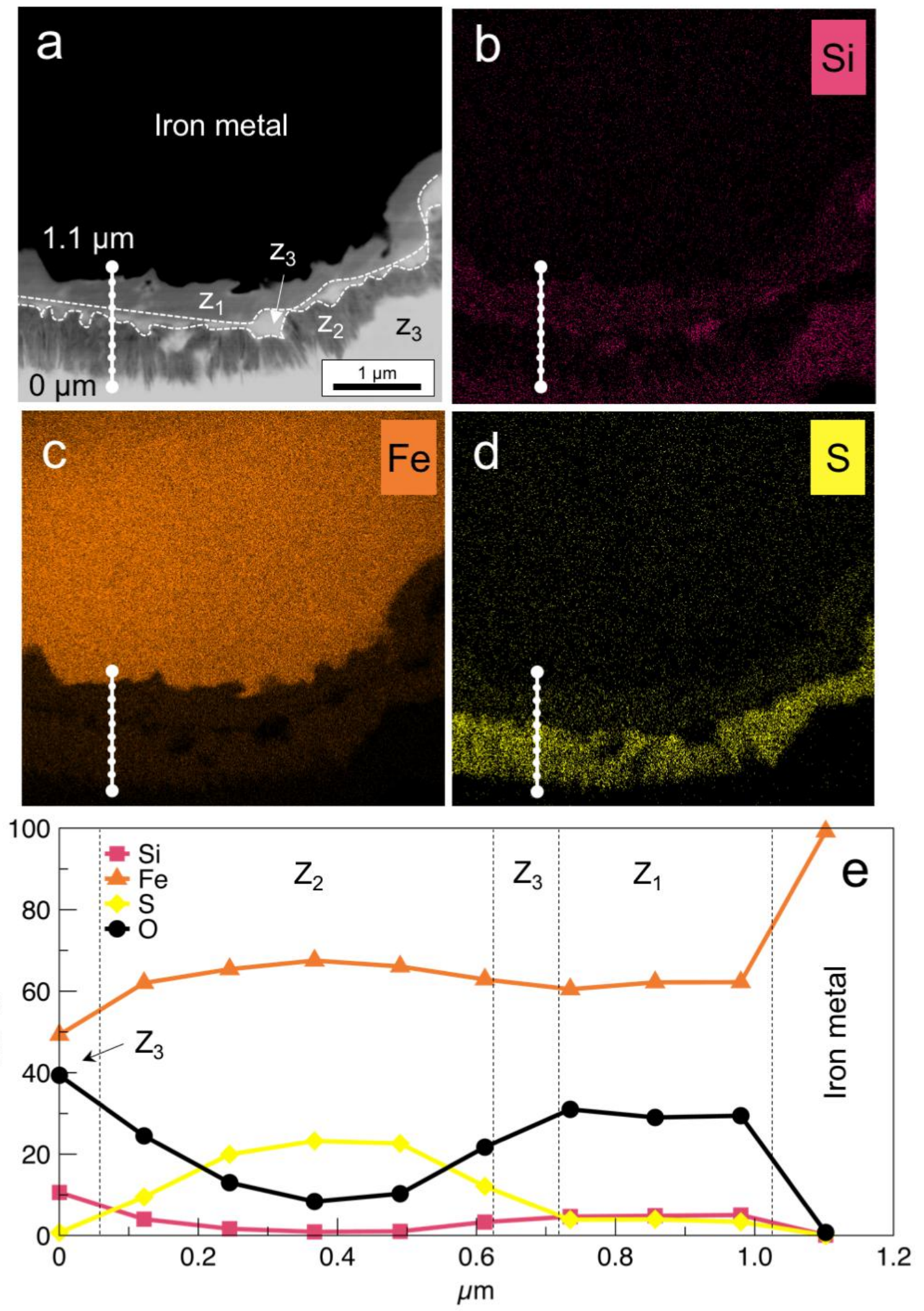

940

941

942

Figure 7 
943

944

945

946

$$
45
$$
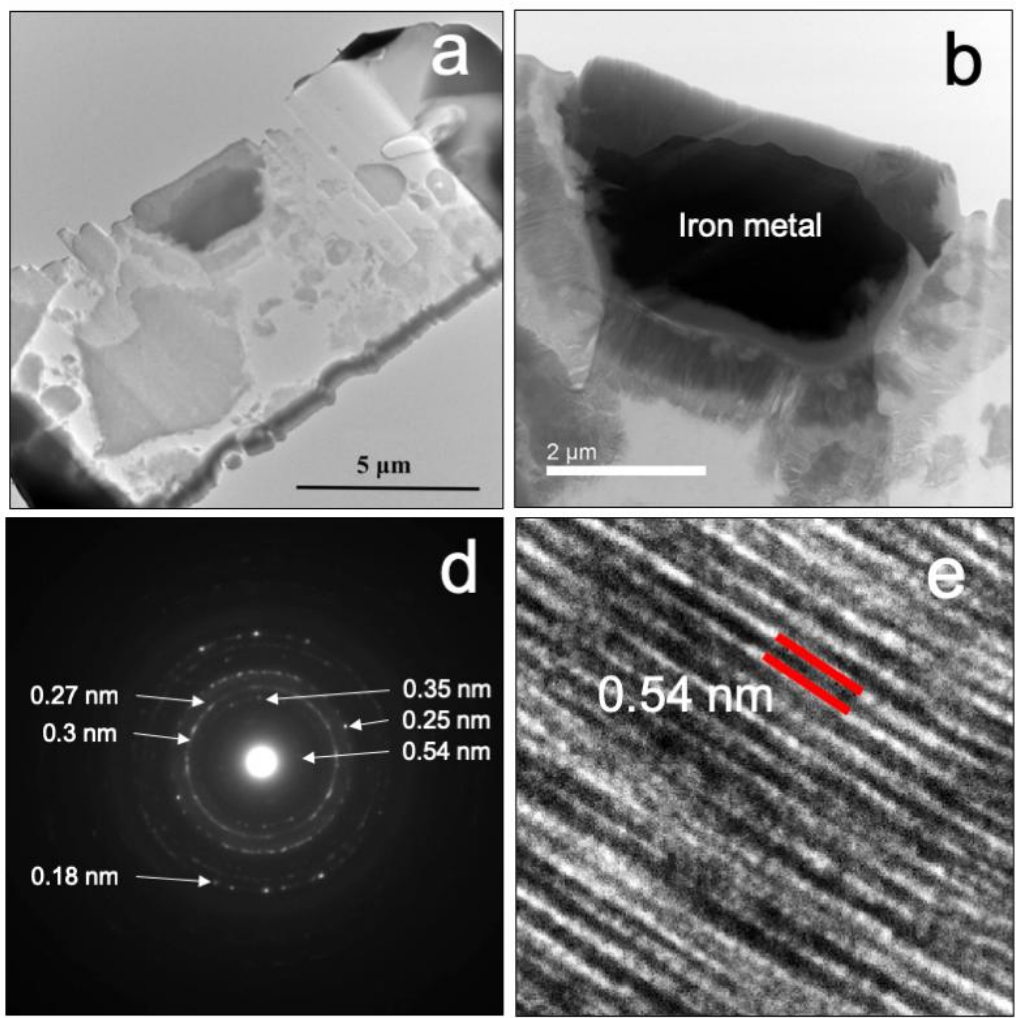

Figure 8
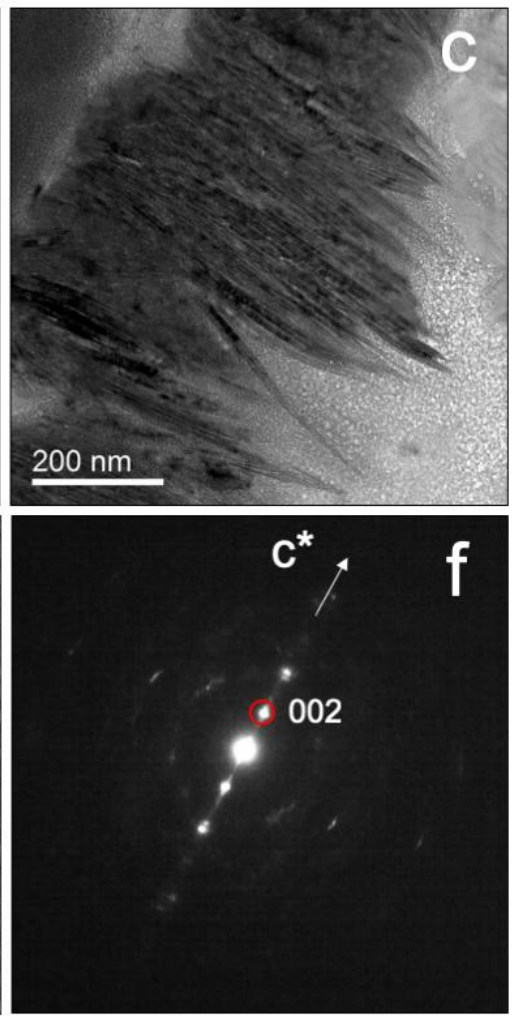


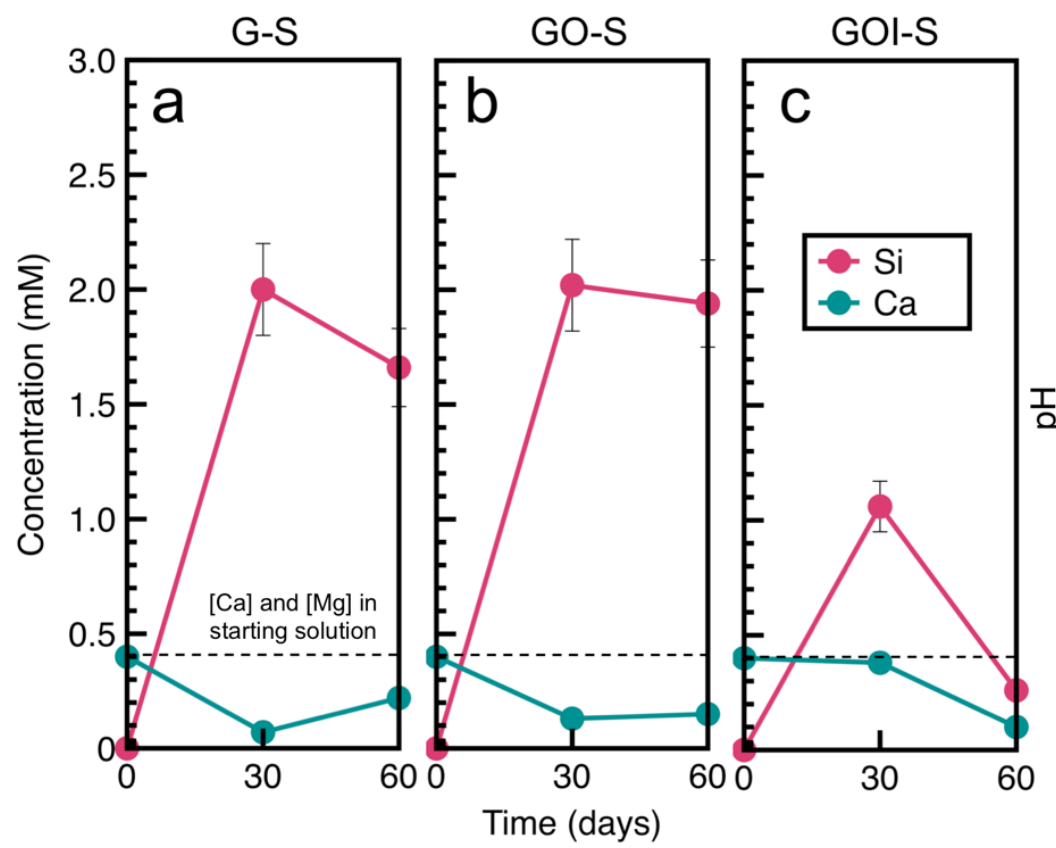

Figure 9

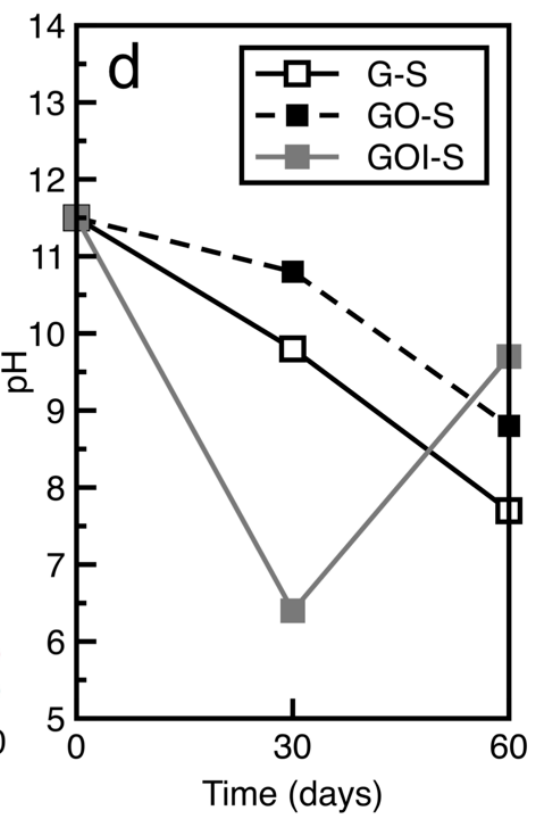




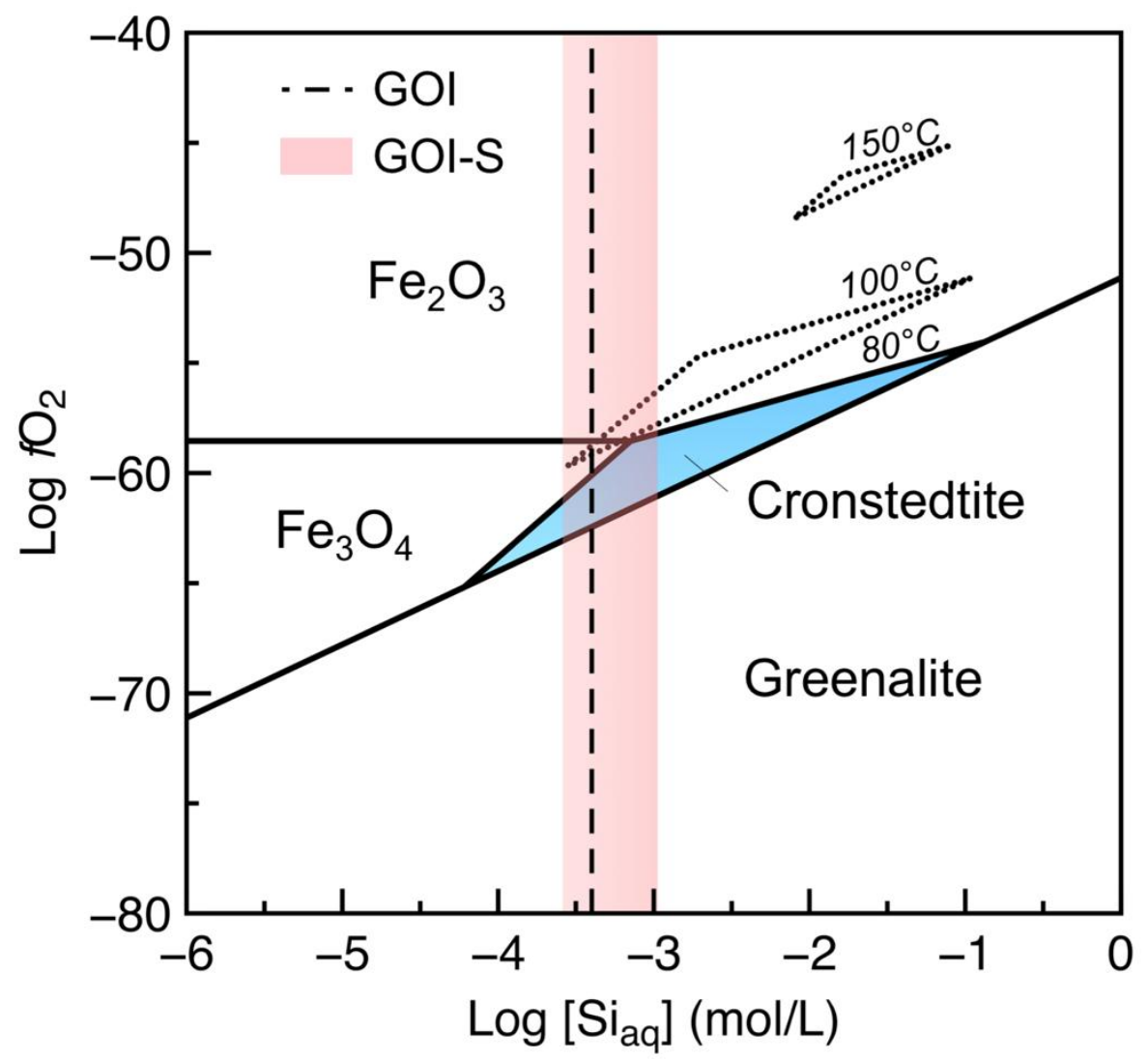

951

952

Figure 10

953

954 


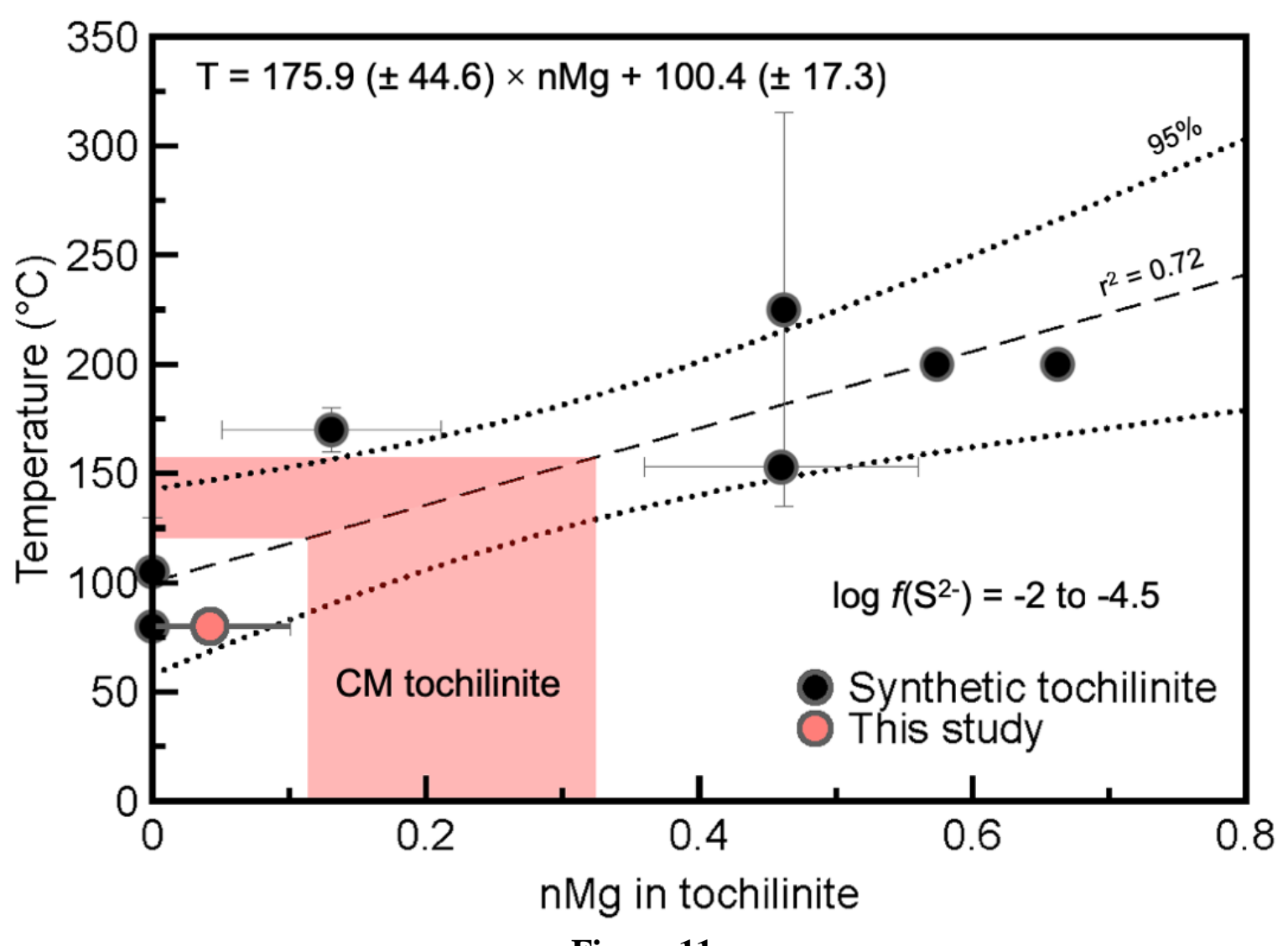




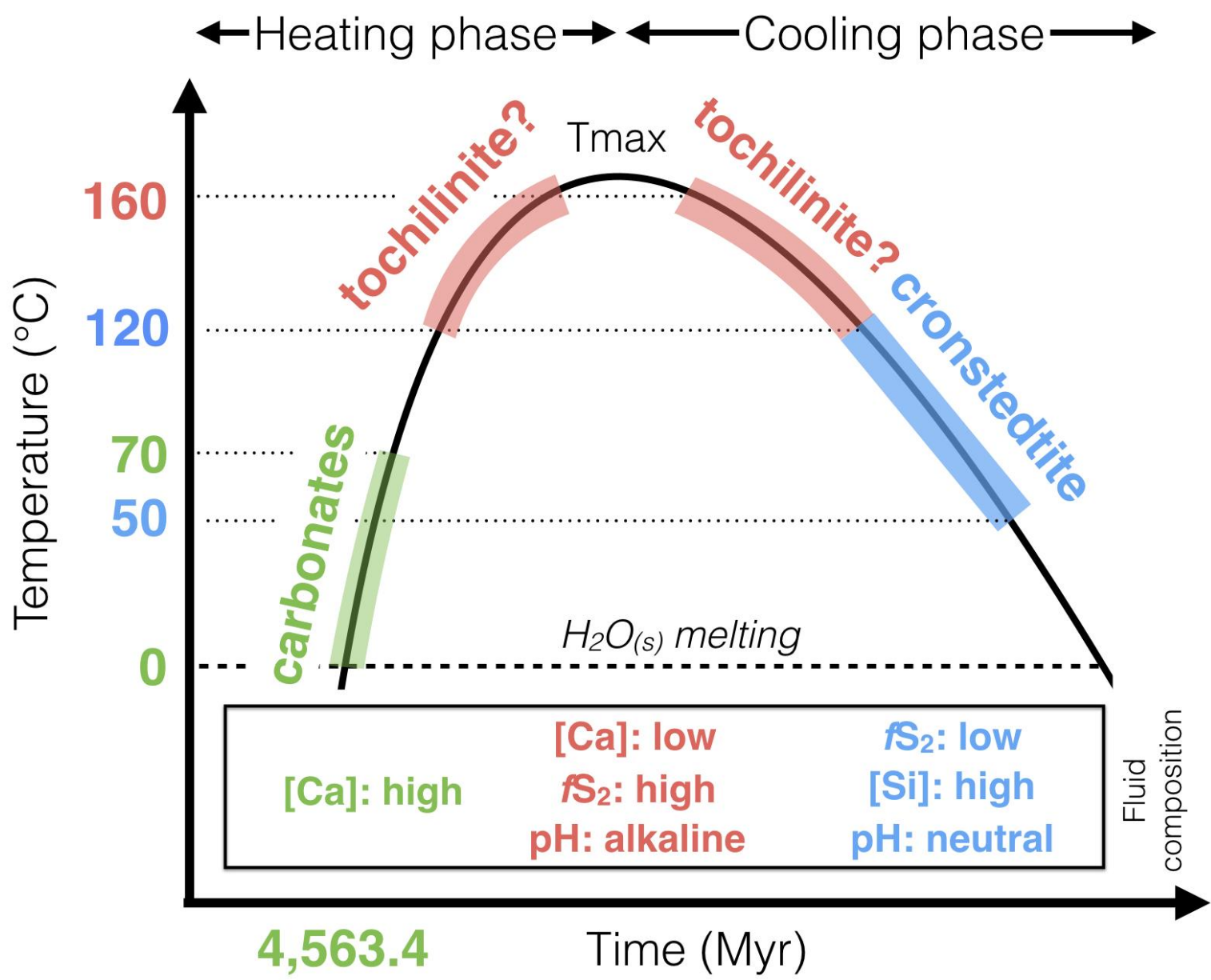

962

Figure 12

963

964 
Expected range of $\log f\left(\mathrm{O}_{2}\right)$ values for cronstedtite at $80^{\circ} \mathrm{C}$

Expected range of $\log f\left(\mathrm{O}_{2}\right)$ values for tochilinite at $80^{\circ} \mathrm{C}$

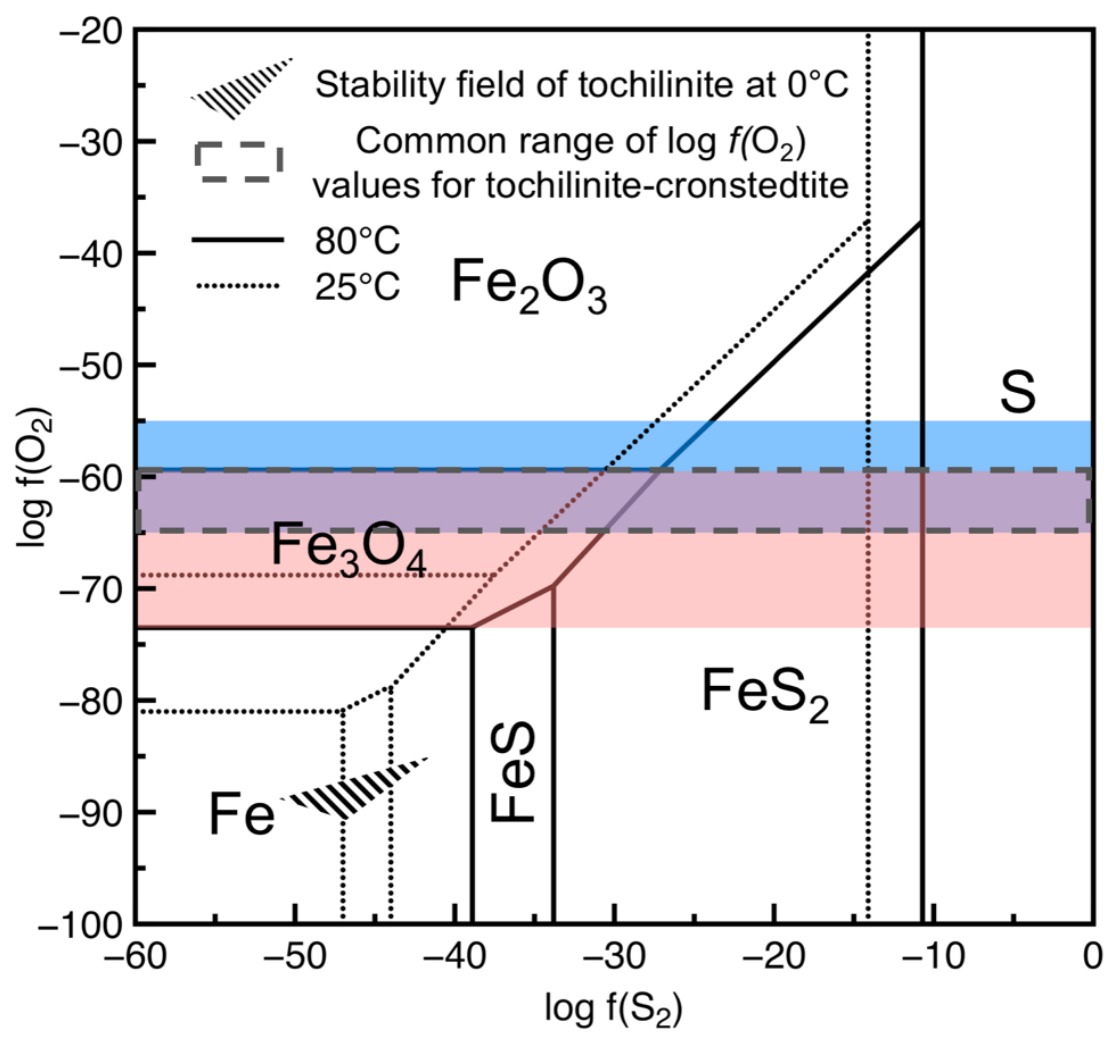

Figure 13 
Table 1. Summary of anoxic experimental conditions at $80^{\circ} \mathrm{C}$ and water/rock ratio $=10$, and

970 the mineral assemblages synthesized.

972 Table 2. Summary of hydrothermal syntheses of cronstedtite and (Fe, Mg,Al)-tochilinite.

Table 1

\begin{tabular}{|c|c|c|c|c|c|c|}
\hline Run \# & $\begin{array}{c}\begin{array}{c}\text { Synthetic GEMS-like } \\
\text { glass (g) }\end{array} \\
\end{array}$ & $\begin{array}{c}\text { Olivine } \\
\text { (g) }\end{array}$ & $\begin{array}{c}\text { Iron metal } \\
(\mathrm{g})\end{array}$ & $\begin{array}{l}\mathrm{Na}_{2} \mathrm{~S} \\
(\mathrm{mM})\end{array}$ & $\begin{array}{c}\text { Time } \\
(\text { d) }\end{array}$ & $\begin{array}{c}\text { Minerals } \\
\text { synthesized } *\end{array}$ \\
\hline \multicolumn{7}{|c|}{ S-free circumneutral fluid (starting $\mathrm{pH}=6.5$ at $25^{\circ} \mathrm{C}$ ) } \\
\hline G-1 & 1 & 0 & $<0.01$ & 0 & 30 & \multirow{4}{*}{$(\mathrm{Fe})-\mathrm{Ph}+\mathrm{Go}$} \\
\hline G-2 & 1 & 0 & $<0.01$ & 0 & 60 & \\
\hline GO-1 & 0.5 & 0.5 & $<0.01$ & 0 & 30 & \\
\hline GO-2 & 0.5 & 0.5 & $<0.01$ & 0 & 60 & \\
\hline GOI-1 & 0.33 & 0.33 & 0.34 & 0 & 30 & \multirow{2}{*}{$\mathbf{C r}+\mathrm{Go}+(\mathrm{Fe})-\mathrm{Ph}$} \\
\hline GOI-2 & 0.33 & 0.33 & 0.34 & 0 & 60 & \\
\hline \multicolumn{7}{|c|}{ S-bearing alkaline fluid (starting $\mathrm{pH}=11.5$ at $25^{\circ} \mathrm{C}$ ) } \\
\hline GS-1 & 1 & 0 & $<0.01$ & 10 & 30 & \multirow{6}{*}{$\begin{array}{c}(\mathbf{F e})-\mathbf{T o}+(\mathrm{Fe})-\mathrm{Ph}+ \\
\text { Ox }\end{array}$} \\
\hline GS-2 & 1 & 0 & $<0.01$ & 10 & 60 & \\
\hline GOS-1 & 0.5 & 0.5 & $<0.01$ & 10 & 30 & \\
\hline GOS-2 & 0.5 & 0.5 & $<0.01$ & 10 & 60 & \\
\hline GOIS-1 & 0.33 & 0.33 & 0.34 & 10 & 30 & \\
\hline GOIS-2 & 0.33 & 0.33 & 0.34 & 10 & 60 & \\
\hline
\end{tabular}

*(Fe)-Ph: Fe,Si-rich phyllosilicate; Mt: magnetite; Cr: cronstedtite; (Fe)-To: Fe-rich tochilinite; Go:

Table 2

\begin{tabular}{|c|c|c|c|c|c|}
\hline Mineral & $\begin{array}{c}\text { Time } \\
\text { (days) }\end{array}$ & $\begin{array}{l}\text { Temp. } \\
\left({ }^{\circ} \mathbf{C}\right)\end{array}$ & pH & Starting material & Authors \\
\hline Cronstedtite & $\begin{array}{c}-120 \\
45 \\
\end{array}$ & 80 & $\begin{array}{l}\text { Neutral- } \\
\text { alkaline }\end{array}$ & Smectite + iron metal & $\begin{array}{c}\text { Lantenois et al. } 2005 \\
\text { Lanson et al. } 2012\end{array}$ \\
\hline Cronstedtite & $180-365$ & $40-90$ & Neutral & Claystone + iron metal & Pignatelli et al. 2013,2014 \\
\hline $\begin{array}{l}\text { "Meteoritic" } \\
\text { cronstedtite }\end{array}$ & $20-110$ & $110-160$ & Alkaline & $\begin{array}{c}\text { (Fe, } \mathrm{Mg}, \mathrm{Al}) \text {-metal particle } \\
\text { precursor mixture }\end{array}$ & Peng and Jing 2014 \\
\hline Tochilinite & 2 & 200 & $\begin{array}{l}\text { Neutral- } \\
\text { alkaline }\end{array}$ & $\begin{array}{l}\text { (Mg,Al)-hydroxide gel + iron } \\
\text { chloride (II) }\end{array}$ & Kakos et al. 1993 \\
\hline Fe-Tochilinite & $10-150$ & 80 & $\begin{array}{l}\text { Neutral- } \\
\text { alkaline }\end{array}$ & Iron chloride (II) & Kozerenko et al. 1996 \\
\hline $\begin{array}{l}\text { Fe-Tochilinite } \\
\text { Mg-Tochilinite }\end{array}$ & $30-150$ & $80-360$ & Alkaline & Iron chloride (II) & Kozerenko et al. 2001 \\
\hline Tochilinite & $?$ & $160-180$ & $\begin{array}{l}\text { Medium- } \\
\text { alkaline }\end{array}$ & $\begin{array}{c}\text { Same as Kozerenko et al. } \\
1996 \\
\end{array}$ & $\begin{array}{l}\text { Chistyakova et al. } 2006 \\
\text { Gubaidulina et al. } 2007\end{array}$ \\
\hline $\begin{array}{l}\text { (Fe, } \mathrm{Mg})- \\
\text { Tochilinite }\end{array}$ & $10-45$ & $120-140$ & Alkaline & $\mathrm{Fe}(\mathrm{OH})_{2}+$ metallic $\mathrm{Mg}$ & Moroz et al. 1997 \\
\hline $\begin{array}{l}\text { (Fe, } \mathrm{Mg}, \mathrm{Al})- \\
\text { Tochilinite }\end{array}$ & $\begin{array}{c}4-60 \\
20-110\end{array}$ & $\begin{array}{c}50-120 \\
110-160\end{array}$ & Alkaline & $\begin{array}{l}(\mathrm{Fe}, \mathrm{Mg}, \mathrm{Al}) \text {-metal particle } \\
\text { precursor mixture }\end{array}$ & $\begin{array}{c}\text { Peng et al. } 2007 \\
\text { Peng and Jing } 2014\end{array}$ \\
\hline $\begin{array}{c}\text { Cronstedtite } \\
\text { Fe-Tochilinite }\end{array}$ & $30-60$ & 80 & $\begin{array}{l}\text { Neutral } \\
\text { Alkaline }\end{array}$ & Glass + olivine + iron metal & This study \\
\hline
\end{tabular}


983 Fig. S1. BSE images of olivine grains and synthetic GEMS-like grains before and after 984 hydrothermal experiments. a) Pristine olivine and b) synthetic GEMS-like grains before 985 hydrothermal experiments. c) Expected unaltered olivine and d) synthetic GEMS-like grains at micrometer scale in S-free experiments after 60 days of alteration. e) Expected unaltered

987 olivine and f) synthetic GEMS-like grains at micrometer scale in S-rich experiments after 60 988 days of alteration.

989

990 Table S1. Representative chemical compositions of secondary minerals formed during neutral 991 S-free experiments (normalized to 100\%); '-' indicates analyses below the detection limit.

993 Table S2. Dissolved cation concentrations in the run solutions equilibrated with the different 994 synthetized products at $80^{\circ} \mathrm{C}$ ('-' indicates analyses below the detection limit, i.e., $<50 \mu \mathrm{g} / \mathrm{L}$ ). 995

996 Table S3. Representative chemical compositions of secondary minerals formed during 997 alkaline S-rich experiments (normalized to 100\%); '-' indicates analyses below the detection 998 limit.

1000 Table S4. Sulfur and Mg concentrations, Mg content in the brucite/amakinite-like layer 1001 normalized to $1 \mathrm{~S}(\mathrm{nMg})$, and precipitation temperature of synthetic and meteoritic tochilinite. 1002 Parenthetical values represent standard deviation; 'n.d.' indicates not determined.; 'n' 1003 indicates the number of values used to calculate the mean $\mathrm{nMg}$ value of $\mathrm{CM}$ tochilinites. 1004 Temperature uncertainties were calculated using the error propagation law. 


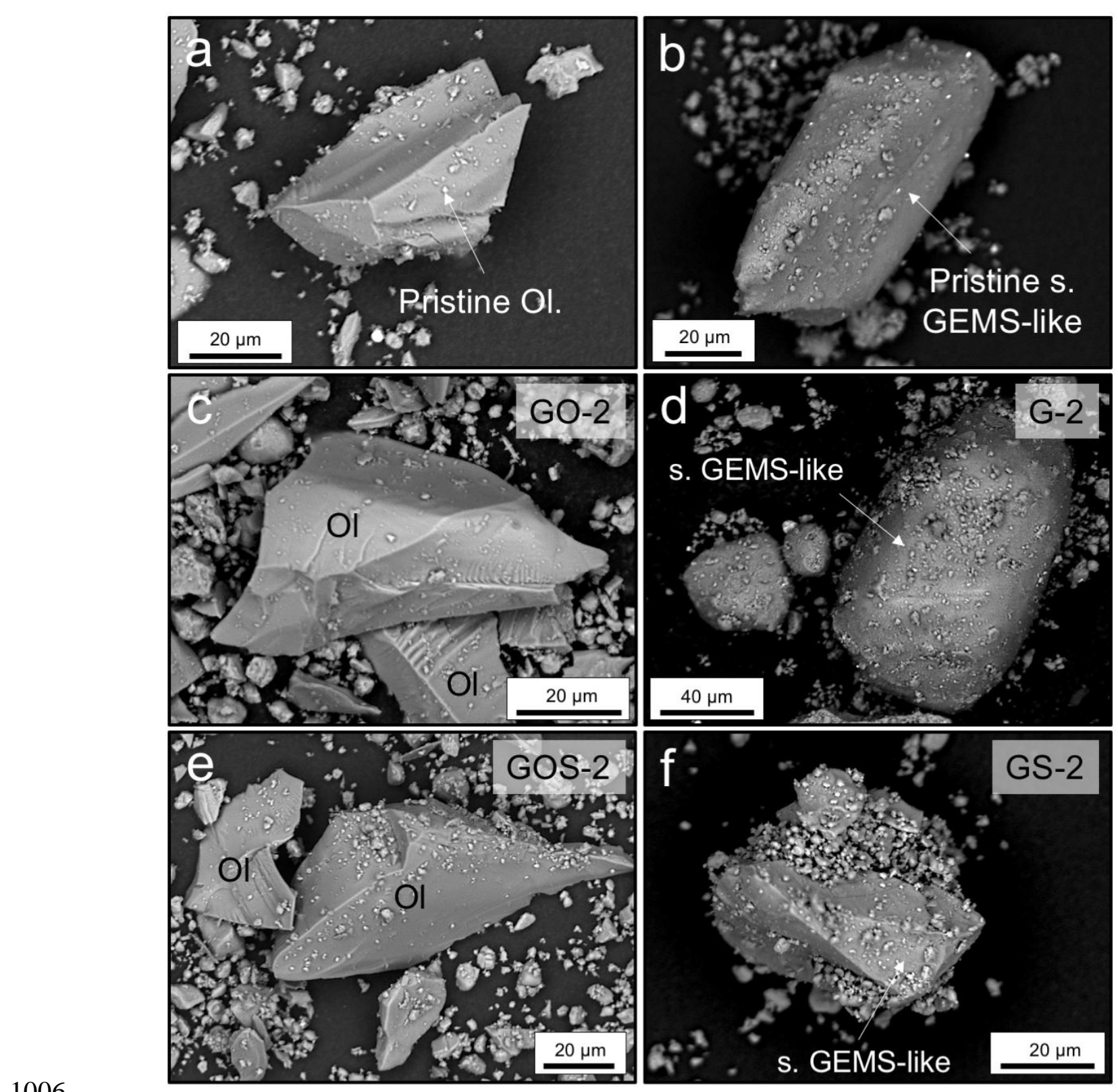

1006

1007

Figure S1

1008 
1009

Table S1.

\begin{tabular}{ccccccccc}
\hline Mineral phase & & Si (wt.\%) & Mg (wt.\%) & Fe (wt.\%) & Ca (wt.\%) & Al (wt.\%) & O (wt.\%) & Total \\
\hline Iron oxide & $*$ & 3.6 & - & 62.3 & 0.3 & - & 33.6 & 100 \\
(Goethite?) & $*$ & 2.7 & - & 67.5 & - & - & 29.8 & 100 \\
& $*$ & 2.7 & - & 68.6 & - & - & 28.8 & 100 \\
& $*$ & 3.0 & - & 64.2 & - & - & 32.8 & 100 \\
& $*$ & 3.6 & - & 64.3 & - & - & 32.0 & 100 \\
& $*$ & 3.3 & - & 66.8 & - & - & 29.8 & 100 \\
& $*$ & 2.9 & - & 66.6 & - & - & 30.5 & 100 \\
& $*$ & 2.9 & - & 66.2 & - & - & 30.9 & 100 \\
& $*$ & 4.5 & 1.1 & 62.4 & - & - & 32.1 & 100 \\
& $*$ & 3.1 & - & 66.4 & - & - & 30.5 & 100 \\
Mean & $*$ & 3.5 & - & 64.4 & - & - & 31.7 & 100 \\
\hline StDev & & $\mathbf{3 . 2}$ & $\mathbf{0 . 1}$ & $\mathbf{6 5 . 4}$ & $\mathbf{0 . 0 3}$ & - & $\mathbf{3 1 . 1}$ & 1.5 \\
\hline Fibrous Fe,Si-rich & $\&$ & 18.1 & 3.7 & 30.9 & 0.9 & 6.3 & 40.1 & 100 \\
& $\&$ & 15.6 & 1.9 & 36.9 & 1.6 & 3.9 & 40.2 & 100 \\
\hline Mean & & $\mathbf{1 6 . 9}$ & $\mathbf{2 . 8}$ & $\mathbf{3 3 . 9}$ & $\mathbf{1 . 3}$ & $\mathbf{5 . 1}$ & $\mathbf{4 0 . 2}$ & \\
StDev & & 1.8 & 1.3 & 4.2 & 0.5 & 1.7 & 0.1 & 1.7 \\
\hline Cronstedtite & $\&$ & 8.6 & 0.6 & 53.3 & 0.2 & 1.7 & 35.5 & 100 \\
& $\&$ & 8.6 & 0.5 & 49.6 & 0.2 & 1.5 & 39.6 & 100 \\
& $\&$ & 7.9 & 0.4 & 55.5 & 0.1 & 1.4 & 34.7 & 100 \\
& $\&$ & 8.6 & 0.4 & 52.2 & 0.1 & 1.2 & 37.4 & 100 \\
& $\&$ & 7.7 & 0.4 & 53.7 & 0.1 & 1.3 & 36.9 & 100 \\
StDev & $\&$ & 8.5 & 0.3 & 52.6 & 0.2 & 1.1 & 37.4 & 100 \\
\hline Mean & & $\mathbf{8 . 3}$ & $\mathbf{0 . 4}$ & $\mathbf{5 2 . 8}$ & $\mathbf{0 . 2}$ & $\mathbf{1 . 4}$ & $\mathbf{3 6 . 9}$ & 1.7 \\
\hline
\end{tabular}

$1010 *$ Data from SEM-EDS analyses.

1011 \& Data from TEM-EDS analyses.

1012 
Table S2.

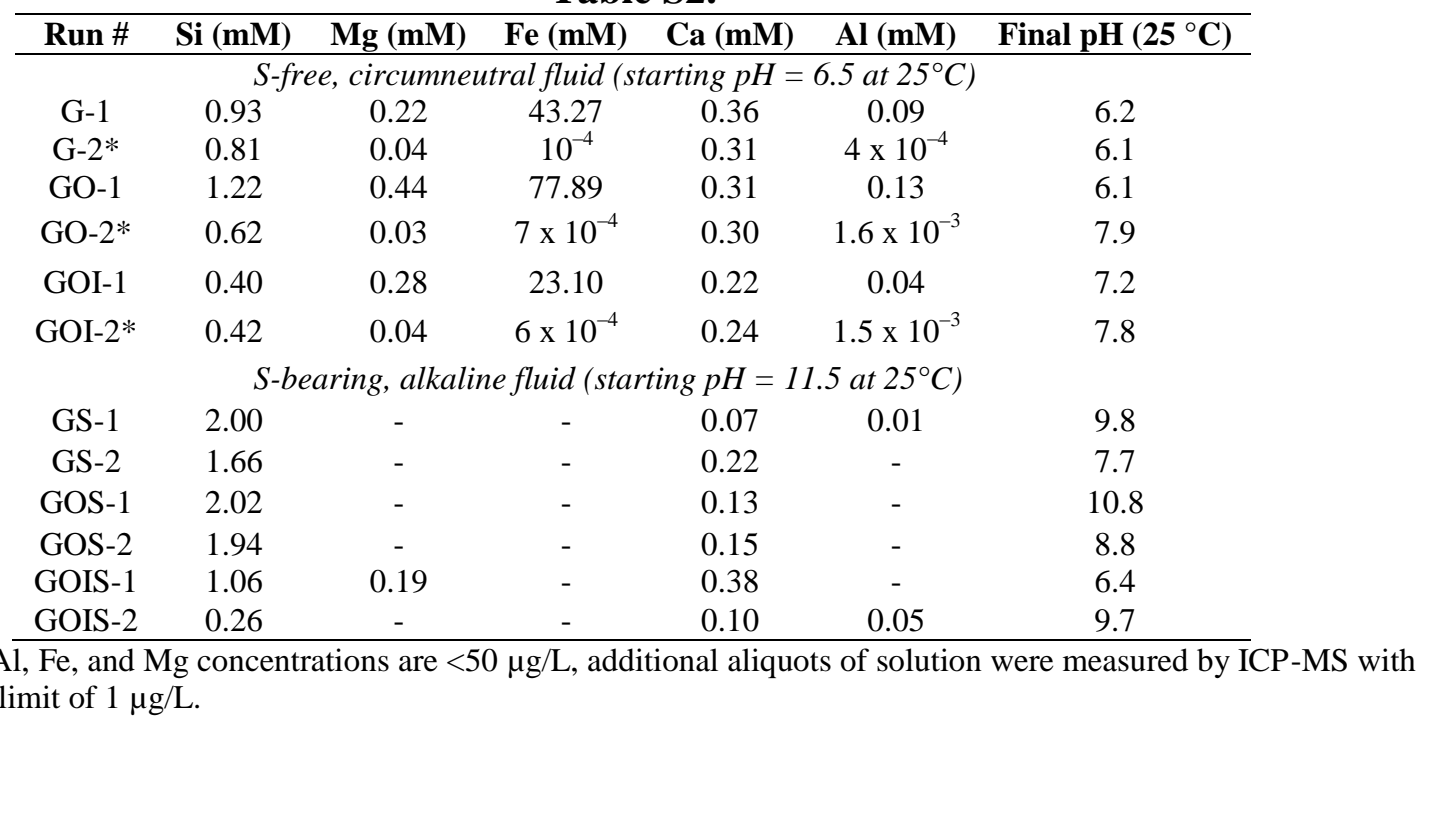

$1014 *$ Because Al, Fe, and Mg concentrations are $<50 \mu \mathrm{g} / \mathrm{L}$, additional aliquots of solution were measured by ICP-MS with 1015 a detection limit of $1 \mu \mathrm{g} / \mathrm{L}$.

1016

1017 
1018

\begin{tabular}{|c|c|c|c|c|c|c|c|c|c|}
\hline Mineral phase & & Si (wt.\%) & Mg (wt.\%) & Fe (wt.\%) & Ca (wt.\%) & Al (wt.\%) & O (wt.\%) & S (wt.\%) & Total \\
\hline \multirow[t]{6}{*}{ Fe-rich layer } & $*$ & 6.6 & 0.0 & 53.3 & 0.5 & 0.4 & 34.0 & 5.2 & 100 \\
\hline & $*$ & 7.3 & 0.0 & 47.9 & 0.7 & 0.3 & 36.9 & 7.1 & 100 \\
\hline & $*$ & 7.8 & 0.0 & 43.6 & 1.3 & 0.4 & 39.7 & 7.2 & 100 \\
\hline & $*$ & 7.1 & 0.0 & 54.9 & 1.4 & 0.4 & 29.9 & 6.4 & 100 \\
\hline & $*$ & 10.3 & 1.0 & 42.1 & 2.4 & 0.9 & 37.5 & 5.7 & 100 \\
\hline & $*$ & 7.4 & 0.0 & 47.3 & 0.9 & 0.3 & 35.7 & 8.5 & 100 \\
\hline Mean & & 7.7 & 0.2 & 48.2 & 1.2 & 0.5 & 35.6 & 6.7 & \\
\hline StDev & & 1.3 & 0.4 & 5.1 & 0.7 & 0.2 & 3.4 & 1.2 & \\
\hline $\mathrm{Fe}, \mathrm{Si}$-rich layer & $*$ & 24.2 & 3.6 & 32.6 & 2.2 & 1.9 & 34.4 & 1.2 & 100 \\
\hline Mean & & 23.3 & 2.7 & 33.4 & 2.0 & 1.8 & 36.2 & 0.6 & \\
\hline StDev & & 1.2 & 1.2 & 1.2 & 0.2 & 0.1 & 2.5 & 0.9 & \\
\hline \multirow[t]{6}{*}{ Tochilinite } & $*$ & 6.5 & 2.1 & 46.5 & 1.2 & 0.9 & 25.4 & 17.4 & 100 \\
\hline & $*$ & 5.8 & 0.8 & 49.5 & 1.0 & 0.8 & 21.2 & 20.9 & 100 \\
\hline & $*$ & 4.6 & 0.4 & 52.9 & 1.9 & 0.4 & 23.4 & 16.6 & 100 \\
\hline & \& & 2.8 & 0.1 & 64.4 & 0.0 & 0.4 & 15.2 & 17.2 & 100 \\
\hline & $\&$ & 2.5 & 0.0 & 66.9 & 0.0 & 0.6 & 12.6 & 17.3 & 100 \\
\hline & $\&$ & 1.4 & 0.3 & 67.5 & 0.0 & 0.3 & 12.4 & 18.1 & 100 \\
\hline Mean & & 3.9 & 0.6 & 57.9 & 0.7 & 0.6 & 18.4 & 17.9 & \\
\hline StDev & & 2.0 & 0.8 & 9.4 & 0.8 & 0.2 & 5.7 & 1.5 & \\
\hline
\end{tabular}

1019 * Data from SEM-EDS analyses.

$1020 \quad \boldsymbol{\&}_{\text {Data from TEM-EDS analyses. }}$

1021
Table S3.

wt. \%

36.9

39.7

37.5

35.7

100 
Table S4.

\begin{tabular}{|c|c|c|c|c|c|}
\hline Meteorite & S (wt.\%) & Mg (wt.\%) & nMg & Temperature $\left({ }^{\circ} \mathrm{C}\right)$ & Authors \\
\hline & \multicolumn{5}{|c|}{ Synthetic tochilinite } \\
\hline & $17.9(1.5)$ & $0.6(0.8)$ & $0.04(0.06)$ & 80 & This study \\
\hline & n.d. & n.d. & 0 & 80 & Kozerenko et al. 1996 \\
\hline & n.d. & n.d. & 0 & $80-130$ & Kozerenko et al. 2001 \\
\hline & $15.1(7.3)$ & $7.1(3.8)$ & $0.46(0.1)$ & 153 & Peng and Jing 2014 \\
\hline & n.d. & n.d. & $0.13(0.08)$ & $160-170$ & Chistyakova et al. 2006 \\
\hline & n.d. & n.d. & 0.57 & 200 & Kakos et al. 1994 \\
\hline & n.d. & n.d. & 0.66 & 200 & Kakos et al. 1994 \\
\hline & n.d. & n.d. & 0.46 & $130-320$ & Kozerenko et al. 2001 \\
\hline & \multicolumn{5}{|c|}{ Meteoritic tochilinite (calculated temperatures) } \\
\hline Paris & $18.8(0.1)$ & $1.6(0.1)$ & $0.12(0.004)$ & $122 \pm 38$ & Pignatelli et al. $2017(n=2)$ \\
\hline Murchison & $19(1.7)$ & $2.6(0.2)$ & $0.18(0.02)$ & $132 \pm 43$ & Palmer and Lauretta $2011(n=3)$ \\
\hline Murray & $19.7(2.9)$ & $2.4(0.3)$ & $0.17(0.04)$ & $130 \pm 50$ & Palmer and Lauretta $2011(\mathrm{n}=3)$ \\
\hline Cold Bokkeveld & $19.5(0.7)$ & $4.5(0.2)$ & $0.32(0.004)$ & $157 \pm 48$ & Palmer and Lauretta $2011(\mathrm{n}=1)$ \\
\hline Nogoya & 18 & 4.2 & 0.3 & $153 \pm 47$ & Palmer and Lauretta $2011(n=1)$ \\
\hline
\end{tabular}

